\title{
CÁRIE DE SUPERFÍCIE RADICULAR: COMPARAÇÃO DOS MÉTODOS DE KATZ E DA ORGANIZAÇÃO MUNDIAL DA SAÚDE
}

\section{MARLÍVIA GONÇALVES DE CARVALHO WATANABE}

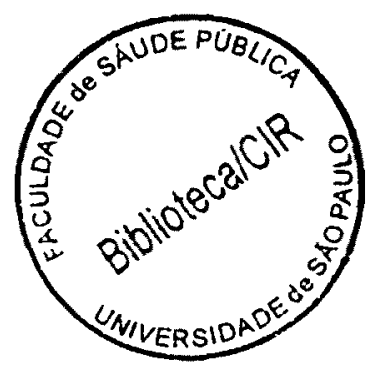

Tese de Doutorado apresentada ao Departamento de Prática de Saúde Pública da Faculdade de Saúde Pública da Universidade de São Paulo para obtenção do Grau de Doutor.

Área de Concentração: Serviços de Saúde Pública

Orientador: Prof. Dr. ROBERTO AUGUSTO CASTELLANOS FERNANDEZ

São Paulo 
Autorizo, exclusivamente para fins acadêmicos e científicos, a reprodução total ou parcial desta tese, por processos fotocopiadores.

Assinatura: dogde lomallo

Data: $\quad 06 / 11 / 2000$

$$
40701 / 2001(d 00)
$$


À minha família, pela presença, pelo apoio, pelo amor... enfim, por tudo. 


\section{AGRADECIMENTOS}

Os meus sinceros agradecimentos ao Prof. Dr. ROBERTO AUGUSTO CASTELLANOS FERNANDEZ pela confiança, orientação e incentivo à realização deste trabalho.

À Prof $f^{a}$ Dra . MARIA DO ROSÁRIO DIAS DE OLIVEIRA LATORRE pela orientação na análise estatística.

Ao Dorival Gaspar pela contribuição e incentivo durante a realização dos exames.

Aos companheiros de trabalho da área de Odontologia em Saúde Coletiva do Departamento de Clínica Infantil, Odontologia Preventiva e Social da Faculdade de Odontologia de Ribeirão Preto - USP pelo espírito de equipe que norteia as atividades desenvolvidas.

Aos docentes e funcionários das clínicas das disciplinas de Diagnóstico Clínico e Periodontia da Faculdade de Odontologia de Ribeirão Preto - USP pela colaboração na realização dos exames.

Aos pacientes que participaram deste estudo por possibilitarem o exame. 


\section{RESUMO}

Watanabe MGC. Cárie de superfície radicular: comparação entre os métodos de KATZ e da Organização Mundial da Saúde. São Paulo; 2000. [Tese de Doutorado - Faculdade de Saúde Pública da USP].

Introdução. A comunidade científica vem discutindo, ao longo das duas últimas décadas, a necessidade e importância da padronização de critérios para avaliação de cárie de superficie radicular. Em 1980, KATZ propôs o Índice de Cárie Radicular (ICR) e em 1997 a Organização Mundial da Saúde (OMS) publicou, pela primeira vez, critérios para avaliação desta doença. O objetivo deste estudo foi verificar a concordância dos resultados obtidos por estes dois métodos para exame de cárie de superficie radicular. Metodologia. Ambos os métodos foram aplicados em 67 pacientes de uma clínica de ensino, com idade igual ou superior a 35 anos de ambos os sexos. O exame foi realizado em cadeira normal, sob luz natural. Resultados. Os dados mostraram que o número médio de dentes com lesões radiculares foi semelhante em ambos os métodos (1,96 para o método proposto por KATZ e 1,43 para o método proposto pela OMS). O ICR médio foi de $16,21 \%$. Houve um maior número de lesões de cárie registradas na raiz pelo método proposto por KATZ. Apesar disso, a concordância entre os métodos foi considerada boa $(k=0,798)$. Conclusões. Ambos os métodos para exame de cárie de superficie radicular mostraram resultados semelhantes do ponto de vista estatístico.

Descritores: Epidemiologia. Cárie Radicular. Índice. 


\section{SUMMARY}

Watanabe MGC. Cárie de superfície radicular: comparação entre os métodos de KATZ e da Organização Mundial da Saúde [ Root surface caries: comparison between the methods of KATZ and World Health Organization ]. São Paulo (BR); 2000. [Tese de Doutorado - Faculdade de Saúde Pública da USP].

Introduction. Along the two past decades, the scientific community discussed the necessity and importance of standardized judgments of root surface caries evaluation. At 1980 KATZ suggested the Root Caries Index (RCI) and at 1997 World Health Organization (WHO) published, at the first time, judgments to evaluation of this disease. The purpose of this study was to compare the results obtained in the application of the two methods, and to verify the agreement of them. Methodology. Both the methods were applied at 67 patients aged 35 years and over. The examination was realized with natural ligth. Results. The mean number of teeth with root lesions per person was similar by the two methods (1,96 for KATZ method and 1,43 by WHO method). The mean ICR was $16,21 \%$. The number of root lesions detected with KATZ method was greater then with WHO method. Despite this, the agreement of the methods was considered good $(k=0,798)$. Conclusions. Both the methods of diagnosing root surface caries showed similar results at the statistical point of view.

Descriptors: Epidemiology. Root Caries. Index. 


\section{ÍNDICE}

1 INTRODUÇÃO 1

2 REVISÃO DA LITERATURA 5

2.1 A Ocorrência de Cárie de Superfície Radicular 6

2.2 A Medição da Ocorrência de Cárie de Superfície Radicular 13

3 OBJETIVO 23

4 MATERIAL E MÉTODOS 25

$\begin{array}{ll}4.1 \text { Treinamento } & 26\end{array}$

4.2 População de Estudo $\quad 26$

$\begin{array}{ll}4.3 \text { Exames } & 26\end{array}$

$\begin{array}{ll}4.4 \text { Condições de Exame } & 27\end{array}$

4.5 Índices, Critérios e Registro $\quad 27$

4.6 Análise dos Resultados

5 RESULTADOS $\quad 35$

5.1 Ocorrência de Cárie de Superfície Radicular segundo KATZ (1980), modificado e complementado em 1986, 1990 e 1996

5.2 Ocorrência de Cárie de Superficie Radicular segundo a Organização Mundial da Saúde (WHO,1997) 44

5.3 Ocorrência de Cárie de Superfície Radicular segundo Ambos os Métodos 46

6 DISCUSSÃo $\quad 60$

7 CONCLUSÕES

8 REFERÊNCIAS BIBLIOGRÁFICAS

$\begin{array}{ll}\text { ANEXOS } & 79\end{array}$

Anexo 1- Ficha para aplicação do método de avaliação proposto por KATZ (1980), modificado e complementado em 1986, 1990 e 1996 al

Anexo 2- Ficha para aplicação do método de avaliação proposto pela Organização Mundial da Saúde (1997) a2 


\section{LISTA DE TABELAS}

Tabela 1 - Distribuição do número e da porcentagem de pessoas segundo a faixa etária e o sexo. p. 36

Tabela 2 - Distribuição do número e da porcentagem de pessoas segundo o número de dentes com lesão de cárie de superfície radicular, de acordo com o método proposto por KATZ (1980), modificado e complementado em 1986, 1990 e 1996.p. 37

Tabela 3 - Distribuição do número e da porcentagem de pessoas examinadas segundo o Índice de Cárie Radicular - ICR (\%). p. 38

Tabela 4 - Distribuição de dentes e superfícies (valores absolutos, proporção e número médio por pessoa), segundo a condição da raiz, de acordo com o método proposto por KATZ (1980), modificado e complementado em 1986, 1990 e 1996. p. 39

Tabela 5 - Número e proporção de superfícies radiculares examinadas segundo localização e presença de recessão gengival e lesões de cárie radicular, de acordo com o método proposto por KATZ (1980), modificado e complementado em 1986, 1990 e 1996. p. 41

Tabela 6 - Número e proporção de superfícies radiculares examinadas segundo localização e presença de recessão gengival e lesões de cárie radicular nas arcadas da boca, de acordo com o método proposto por KATZ (1980), modificado e complementado em 1986, 1990 e 1996. p. 43

Tabela 7 - Distribuição do número e da porcentagem de pessoas segundo o número de dentes com lesão de cárie de superficie radicular, de acordo com o método proposto pela OMS (1997). p. 45

Tabela 8 - Distribuição de dentes (valores absolutos, proporção e número médio por pessoa), segundo a condição da raiz, de acordo com o método proposto pela OMS (1997). p. 45

Tabela 9 - Número de molares superiores direitos de pacientes adultos segundo presença de cárie de superficie radicular (tratada ou não) de acordo com critérios propostos por KATZ (1980), modificado e complementado em 1986, 1990 e 1996, e pela OMS (1997). p. 46

Tabela 10 - Número de molares superiores esquerdos de pacientes adultos segundo presença de cárie de superfície radicular (tratada ou não) de acordo com critérios propostos por KATZ (1980), modificado e complementado em 1986, 1990 e 1996, e pela OMS (1997). p. 47 
Tabela 11 - Número de pré-molares superiores direitos de pacientes adultos segundo presença de cárie de superfície radicular (tratada ou não) de acordo com critérios propostos por KATZ (1980), modificado e complementado em 1986, 1990 e 1996, e pela OMS (1997). p. 47

Tabela 12 - Número de pré-molares superiores esquerdos de pacientes adultos segundo presença de cárie de superfície radicular (tratada ou não) de acordo com critérios propostos por KATZ (1980), modificado e complementado em 1986, 1990 e 1996, e pela OMS (1997). p. 48

Tabela 13 - Número de caninos superiores direitos de pacientes adultos segundo presença de cárie de superfície radicular (tratada ou não) de acordo com critérios propostos por KATZ (1980), modificado e complementado em 1986, 1990 e 1996, e pela OMS (1997). p. 48

Tabela 14 - Número de caninos superiores esquerdos de pacientes adultos segundo presença de cárie de superfície radicular (tratada ou não) de acordo com critérios propostos por KATZ (1980), modificado e complementado em 1986, 1990 e 1996, e pela OMS (1997). p. 49

Tabela 15 - Número de incisivos superiores direitos de pacientes adultos segundo presença de cárie de superfície radicular (tratada ou não) de acordo com critérios propostos por KATZ (1980), modificado e complementado em 1986, 1990 e 1996, e pela OMS (1997). p. 50

Tabela 16 - Número de incisivos superiores esquerdos de pacientes adultos segundo presença de cárie de superfície radicular (tratada ou não) de acordo com critérios propostos por KATZ (1980), modificado e complementado em 1986, 1990 e 1996, e pela OMS (1997). p. 50

Tabela 17 - Número de molares inferiores direitos de pacientes adultos segundo presença de cárie de superfície radicular (tratada ou não) de acordo com critérios propostos por KATZ (1980), modificado e complementado em 1986, 1990 e 1996, e pela OMS (1997). p. 50

Tabela 18 - Número de molares inferiores esquerdos de pacientes adultos segundo presença de cárie de superfície radicular (tratada ou não) de acordo com critérios propostos por KATZ (1980), modificado e complementado em 1986, 1990 e 1996, e pela OMS (1997). p. 51

Tabela 19 - Número de pré-molares inferiores direitos de pacientes adultos segundo presença de cárie de superfície radicular (tratada ou não) de acordo com critérios propostos por KATZ (1980), modificado e complementado em 1986, 1990 e 1996, e pela OMS (1997). p. 51

Tabela 20 - Número de pré-molares inferiores esquerdos de pacientes adultos segundo presença de cárie de superficie radicular (tratada ou não) de 
acordo com critérios propostos por KATZ (1980), modificado e complementado em 1986, 1990 e 1996, e pela OMS (1997), p. 52

Tabela 21- Número de caninos inferiores direitos de pacientes adultos segundo presença de cárie de superfície radicular (tratada ou não) de acordo com critérios propostos por KATZ (1980), modificado e complementado em 1986, 1990 e 1996, e pela OMS (1997). p. 52

Tabela 22 - Número de caninos inferiores esquerdos de pacientes adultos segundo presença de cárie de superficie radicular (tratada ou não) de acordo com critérios propostos por KATZ (1980), modificado e complementado em 1986, 1990 e 1996, e pela OMS (1997), p. 53

Tabela 23 - Número de incisivos inferiores direitos de pacientes adultos segundo presença de cárie de superfície radicular (tratada ou não) de acordo com critérios propostos por KATZ (1980), modificado e complementado em 1986, 1990 e 1996, e pela OMS (1997). p. 53

Tabela 24 - Número de incisivos inferiores esquerdos de pacientes adultos segundo presença de cárie de superfície radicular (tratada ou não) de acordo com critérios propostos por KATZ (1980), modificado e complementado em 1986, 1990 e 1996, e pela OMS (1997). p. 53

Tabela 25 - Número de dentes do quadrante inferior direito de pacientes adultos segundo presença de cárie de superfície radicular (tratada ou não) de acordo com critérios propostos por KATZ (1980), modificado e complementado em 1986, 1990 e 1996, e pela OMS (1997). p. 54

Tabela 26 - Número de dentes do quadrante inferior esquerdo de pacientes adultos segundo presença de cárie de superfície radicular (tratada ou não) de acordo com critérios propostos por KATZ (1980), modificado e complementado em 1986, 1990 e 1996, e pela OMS (1997). p. 55

Tabela 27 - Número de dentes do quadrante superior esquerdo de pacientes adultos segundo presença de cárie de superfície radicular (tratada ou não) de acordo com critérios propostos por KATZ (1980), modificado e complementado em 1986, 1990 e 1996, e pela OMS (1997). p. 55

Tabela 28 - Número de dentes do quadrante superior direito de pacientes adultos segundo presença de cárie de superfície radicular (tratada ou não) de acordo com critérios propostos por KATZ (1980), modificado e complementado em 1986, 1990 e 1996, e pela OMS (1997). p. 56

Tabela 29 - Número de dentes da arcada superior de pacientes adultos segundo presença de cárie de superfície radicular (tratada ou não) de acordo com critérios propostos por KATZ (1980), modificado e complementado em 1986, 1990 e 1996, e pela OMS (1997). p. 56 
Tabela 30 - Número de dentes da arcada inferior de pacientes adultos segundo presença de cárie de superfície radicular (tratada ou não) de acordo com critérios propostos por KATZ (1980), modificado e complementado em 1986, 1990 e 1996, e pela OMS (1997).p. 57

Tabela 31 - Número de dentes do lado direito de pacientes adultos segundo presença de cárie de superficie radicular (tratada ou não) de acordo com critérios propostos por KATZ (1980), modificado e complementado em 1986, 1990 e 1996, e pela OMS (1997). p. 57

Tabela 32 - Número de dentes do lado esquerdo de pacientes adultos segundo presença de cárie de superfície radicular (tratada ou não) de acordo com critérios propostos por KATZ (1980), modificado e complementado em 1986, 1990 e 1996, e pela OMS (1997). p. 58

Tabela 33 - Número de dentes de pacientes adultos segundo presença de cárie de superficie radicular (tratada ou não) de acordo com critérios propostos por KATZ (1980), modificado e complementado em 1986, 1990 e 1996, e pela OMS (1997). p. 58 


\section{LISTA DE FIGURAS}

Figura 1 - Índice de Cárie Radicular (ICR) segundo grupos de dentes por arcadas. p. 40

Figura 2 - Número médio de superfícies radiculares atacadas por cárie por pessoa, segundo localização. p. 41

Figura 3 - Índice de Cárie Radicular por superfícies, segundo localização. p. 42

Figura 4 - Número médio de superfícies radiculares atacadas por cárie por pessoa, segundo arcadas da boca e localização. p. 43

Figura 5 - Índice de Cárie Radicular em superficies dentais, segundo arcadas da boca e localização. p. 44 


\section{LISTA DE QUADROS}

Quadro 1 - Comparação entre os critérios para exame de cárie radicular propostos por KATZ (ICR) e pela Organização Mundial da Saúde (OMS). p.21

Quadro 2 - Classificação da concordância, segundo valores do Kappa. p.34 
1-INTRODUÇÃO 
A cárie de superfície radicular tem sido descrita em vários textos (LEIGH, 1935; HARDWICK, 1960 ; CORBETT e MOORE, 1971; MEHTA e SCHROFF, 1965; SCHAMSCHULA e col., 1972; JORDAN e SUMNEY, 1972; BANTING e COURTRIGHT, 1975; BANTING e col., 1980; KATZ e col., 1982; VEHKALAHTI e col., 1983; BECK e col., 1985; LESKE e RIPA, 1989) ao longo deste século, porém os estudos sobre a epidemiologia da doença se intensificaram nas décadas de 70 e 80 . Havia, entretanto, uma grande dificuldade de se compararem os resultados obtidos nos diversos estudos, devido à diversidade de grupos populacionais utilizados, em várias faixas etárias e, principalmente, à ausência de critérios de diagnóstico padronizados, como os conhecidos para cárie coronária e às diferentes formas de apresentação dos resultados obtidos.

Neste sentido, KATZ (1980) fez uma revisão dos trabalhos realizados nos trinta anos anteriores e observou a predominância de três formas utilizadas para relatar a ocorrência de cárie radicular: 1) proporção de pessoas exibindo uma ou mais lesões, 2) número médio de lesões por pessoa e 3) número médio de lesões por dente presente. Com base na observação de que estas medidas não consideravam uma unidade verdadeira de risco à doença, o Autor propôs o Índice de Cárie Radicular (ICR) , o qual expressa a proporção de lesões de cárie radicular em relação às superfícies radiculares expostas ao ambiente bucal devido à recessão gengival. 
Desde então, vários estudos utilizaram o índice proposto (KATZ e col., 1985; GUSTAVSEN e col., 1988; WALLACE e col., 1988; FURE e ZICKERT, 1990; FEJERSKOV e col., 1991); em outros, os autores obtiveram os resultados de seus trabalhos utilizando a mesma forma de cálculo, porém sem se referirem ao índice anteriormente proposto por KATZ, 1980 (RAVALD e HAMP, 1981; RAVALD e col., 1986; BRUSTMAN, 1986) e, ao longo dos anos, algumas críticas foram feitas ao índice, relativas à não inclusão de lesões subgengivais, ao critério adotado para classificar a superfície como apresentando recessão gengival e à não inclusão de dentes perdidos, as quais levaram o próprio Autor a dissertar a respeito em dois momentos (KATZ, 1990; KATZ, 1996), nos quais defendeu o registro de lesões subgengivais como uma entidade a parte; definiu novamente, de forma a dirimir as dúvidas, a classificação de recessão gengival, e insistiu na proposta de não incluir o número de dentes perdidos no cálculo do ICR. Neste período, os Autores mais envolvidos com o estudo da epidemiologia da cárie de superfície radicular, inclusive o próprio $\mathrm{KATZ}$, sugeriram maiores discussões a respeito de uma possível padronização dos critérios na coleta e apresentação de dados relativos à doença.

Em 1997, a Organização Mundial da Saúde-OMS (WHO, 1997) publicou a $4^{\mathrm{a}}$ edição de seu Manual de Orientação para Levantamentos Epidemiológicos em Saúde Bucal, o qual inclui, pela primeira vez, orientações específicas para o registro de cárie de superfície radicular. Estas diferem, em alguns aspectos, da proposta de KATZ (1980). 
Esses acontecimentos motivaram a realização do presente estudo, o qual tem como objetivo geral comparar os métodos de avaliação da ocorrência da cárie de superficie radicular propostos por KATZ (1980), modificado e complementado em 1986, 1990 e 1996, e pela OMS (WHO,1997). 
2- REVISÃO DA LITERATURA 


\section{1- A Ocorrência de Cárie de Superfície Radicular}

A cárie de superfície radicular aflige o homem desde a antigüidade. Estudos relatados por LEIGH (1935), HARDWICK (1960) e CORBETT e MOORE (1971), os quais examinaram crânios de populações antigas, demonstraram que a cárie dentária era um problema pequeno, porém a maioria das lesões se desenvolviam em superficies radiculares.

Sociedades primitivas atuais também tendem a desenvolver mais cárie de superfície radicular que de esmalte, tornando-se, aparentemente, um problema, como afirmam MEHTA e SCHROFF (1965), SCHAMSCHULA e col. (1972) e JORDAN A SUMNEY (1972).

BANTING e COURTRIGHT (1975) concluíram que existem semelhanças entre as lesões de cárie de superfície radicular observadas em civilizações antigas e civilizações atuais que não possuem acesso ao estilo de vida moderno, das quais destacam-se algumas: (1) as lesões de cárie radicular são mais prevalentes nestas populações que as lesões de esmalte; (2) a prevalência de lesões de cárie de superfície radicular aumenta com o avanço da idade e aparecem próximas à junção cemento-esmalte, após a recessão gengival e conseqüente exposição da superfície da raiz.

Vários estudos relataram a ocorrência de cárie de superfície radicular em populações de sociedades industrializadas. A preocupação com a doença aumentou 
nas últimas três décadas, devido ao aumento da população idosa ocorrido nos Estados Unidos e outros países desenvolvidos, acompanhado pela maior permanência dos dentes na boca até os anos posteriores da vida. KATZ (1980) afirmou que o objetivo do tratamento odontológico teria que mudar para satisfazer as necessidades de doenças específicas deste grupo etário, incluindo sua forma predominante de cárie dentária, ou seja, a cárie de superfície radicular. Posteriormente, LESKE e RIPA (1989) colocaram que a cárie dentária havia declinado significativamente em crianças em vários países desenvolvidos, tanto que os recursos dirigidos para cáries coronárias neste grupo poderiam, então, ser aplicados nos adultos.

SUMNEY e col. (1973) examinaram 307 americanos de 30 a 60 anos de idade, através de exame clínico e radiográfico, e observaram que 49,2\% das pessoas possuíam cárie de superfície radicular. As lesões foram notadas com maior freqüência na mandíbula, nos pré-molares inferiores e nas superfícies vestibulares e linguais.

Examinando 59 pacientes de um hospital de Ontario (Canadá) com idade igual ou superior a 39 anos, BANTING e col. (1980) observaram que $88 \%$ dos pacientes apresentaram cárie de superficie radicular, com um número médio de 7,6 lesões e 2,6 restaurações por pessoa. A maioria das lesões $(53 \%)$ foram encontradas em superficies proximais. 
KATZ e col. (1982) realizaram um estudo em que um total de 473 funcionários de uma companhia de seguros americana com idade entre 20 e 64 anos foram examinados em relação à presença de cárie radicular e recessão gengival. Entre os examinados, $42 \%$ possuíam uma ou mais lesões de cárie radicular, sendo que $11,4 \%$ das superfícies com recessão gengival foram atacadas pela doença. Os valores do Índice de Cárie Radicular (ICR), proposto por KATZ (1980), tenderam a aumentar com a idade e serem levemente maiores nas mulheres após os 40 anos de idade. Os padrões de distribuição intra-oral revelaram que os dentes mais freqüentemente atacados por cárie radicular foram os molares inferiores (ICR $=40 \%$ ), os pré-molares inferiores $(\mathrm{ICR}=25 \%)$ e os caninos superiores $(\mathrm{ICR}=23 \%)$. O dentes menos afetados foram os incisivos inferiores $(\mathrm{ICR}=2 \%)$. Em relação às superfícies, as mais atacadas pela doença foram as interproximais no maxilar e as vestibulares na mandíbula.

Um levantamento realizado por VEHKALAHTI e col. (1983) com 5028 adultos finlandeses com idade igual ou superior a 30 anos revelou que $21,6 \%$ dos homens e $14,5 \%$ das mulheres exibiam cárie de superfície radicular. Entre os homens $2,23 \%$ dos dentes foram afetados por cárie radicular, contra $1,19 \%$ entre as mulheres.

BECK e col. (1985) descreveram a prevalência de cárie coronária e radicular e a relação entre as duas doenças em uma população de idosos (igual ou superior a 65 anos) não institucionalizados de dois municípios rurais do estado de Iowa (E.U.A.). Os exames foram realizados clinicamente e restaurações foram incluídas. Entre 520 pessoas dentadas examinadas, 63\% apresentaram alguma lesão de cárie 
radicular, com uma média de 2,3 superficies afetadas por pessoa, sendo $39 \%$ das superficies dentárias com recessão gengival. Cárie coronária evidente foi encontrada em $90 \%$ da população examinada.

Em um levantamento epidemiológico conduzido em pacientes adultos americanos, KATZ e col. (1985) observaram que, entre os 3.361 pacientes de 20 a 79 anos de idade, o ICR (número de superficies radiculares cariadas ou restauradas sobre o número de superfícies radiculares com recessão gengival) foi de $15 \%$, ligeiramente maior nos homens (17\%) que nas mulheres (14\%). Os molares inferiores e superiores e os caninos superiores apresentaram os mais altos valores do ICR $(22-27 \%)$, sendo que os incisivos inferiores apresentaram os menores valores (3\%). Já em relação às superfícies, as interproximais e vestibulares mostraram os maiores valores para o ICR ( 17 e $16 \%$ respectivamente), enquanto que as linguais mostraram os menores valores $(9 \%)$.

GUSTAVSEN e col. (1988), também baseados em dados coletados em pacientes adultos com idade igual ou superior a 20 anos, provenientes de $20 \%$ das clínicas odontológicas da cidade de Bergen (Noruega), observaram que o ICR foi de 21\%. O número médio de superfícies com cárie radicular variou com a idade, de 1,2 na faixa etária de 20 a 29 anos, para 8,5 na faixa etária de 70 anos ou mais. Os dentes póstero-inferiores exibiram os valores mais altos de ICR, ou seja $32,9 \%$, da mesma forma que as superficies interproximais e vestibulares, com ICR variando de 20 a $25 \%$ e 10 a $36 \%$ respectivamente, enquanto que nas linguais, a variação foi de 10 a $17 \%$. 
WALLACE e col. (1988) realizaram um estudo determinando a prevalência de cárie radicular em uma amostra da população idosa residente na cidade de Birmingham (Inglaterra). Foram examinadas 603 pessoas com pelo menos 60 anos de idade e 15 dentes naturais presentes na boca. O ICR foi de $8,1 \%$, sendo que $69,7 \%$ das pessoas examinadas possuíam cárie radicular e 100\% possuíam recessão gengival. Os maiores valores do ICR foram apresentados pelos segundos molares inferiores (28\%) e pelas superficies vestibulares (14\%), contra os menores valores dos incisivos centrais inferiores (2\%) e das superfícies linguais (3\%).

Em outro levantamento realizado em adultos, agora no Canadá (East York), LOCKER e col. (1989), examinando 183 pessoas dentadas com 50 anos ou mais, observaram que $56,8 \%$ das pessoas apresentaram experiência de cárie radicular (uma ou mais superfícies radiculares cariadas ou restauradas) e $37,2 \%$ apresentavam pelo menos uma superfície radicular cariada. O número médio de superfícies radiculares cariadas foi 1,3 por pessoa, e de superfícies radiculares cariadas ou restauradas foi 2,6 .

A prevalência e distribuição intra-oral da cárie de superfície radicular foi avaliada em pessoas com 55, 65 e 75 anos de idade em Gothenburg (Suécia) por FURE e ZICKERT (1990), que encontraram uma ou mais superficies radiculares cariadas ou restauradas em 85,93 e $90 \%$ das pessoas examinadas. Os valores médios do ICR foram $14 \%$ aos 55 anos, $16 \%$ aos 65 anos e $22 \%$ aos 75 anos de idade. As superficies radiculares dos molares foram mais freqüentemente afetadas pela doença. 
$\mathrm{Na}$ maxila, as superfícies proximais apresentaram uma freqüência maior da doença, enquanto que, na mandíbula, foram as superficies vestibulares, sendo a cárie radicular menos freqüente nas superfícies linguais de ambas as arcadas.

HELLYER e col. (1990) realizaram um estudo envolvendo 146 pacientes de uma clinica odontológica da cidade de East Sussex (R.U.), com idade igual ou superior a 55 anos e com um mínimo de 12 dentes naturais. A maior parte das pessoas $(88,4 \%)$ possuía evidência de cárie radicular, sendo esta mais freqüente nos homens que nas mulheres.

Também analisando a ocorrência de lesões de cárie de superfície radicular, FEJERSKOV e col. (1991), através de exame clínico e radiográfico, observaram 1.092 lesões de superfícies radiculares em 91 dinamarqueses (Aarhus) com idade entre 70 e 80 anos, das quais $14,3 \%$ foram diagnosticadas como ativas, $46,6 \%$ inativas e $39,1 \%$ restauradas. A porcentagem de superficies radiculares cariadas ou restauradas em relação às superficies de risco demonstrou que as superfícies vestibulares de molares e pré-molares inferiores e caninos superiores foram as mais severamente afetadas $(\mathrm{ICR}=70 \%)$.

De acordo com KATZ (1985), os estudos demonstram, em geral, que a prevalência de cárie de superfície radicular varia de 20 a $40 \%$ em adultos de países ocidentais industrializados, sendo que, uma vez estabelecida a recessão gengival, 15 a $20 \%$ das superficies radiculares expostas desenvolvem a doença. 
No que diz respeito a grupos populacionais brasileiros, ainda existem poucos estudos que enfoquem a ocorrência de cárie de superficie radicular. Em trabalho de dissertação de Mestrado realizado com um grupo de pessoas brasileiras, WATANABE (1994) examinou 360 pacientes de uma instituição de ensino odontológico de Ribeirão Preto (Brasil) nas faixas etárias de 35 a 44 anos e 50 a 59 anos, com o objetivo de conhecer a prevalência de cárie de superfície radicular nesta população. Foi utilizado o método proposto por KATZ (1980), modificado e complementado em 1986 e 1990. Entre os examinados, o ICR médio foi de 16,67\%. O número médio de superficies radiculares atacadas pela doença foi 4,24 . Os dentes que apresentaram os maiores valores para o ICR foram os molares e pré-molares inferiores e caninos e pré-molares superiores. Em relação às superficies, o maior número de lesões foi observado nas vestibulares e o ICR foi maior nas superfícies proximais na maxila e vestibulares na mandíbula.

SILVA (1999) relatou, em sua tese de Doutorado, os resultados de um estudo realizado com 337 pessoas com idade igual ou superior a 60 anos, pacientes de um Centro de Saúde de Araraquara-SP (Brasil), com o objetivo de avaliar a autopercepção das condições bucais. Entre os examinados, 201 pessoas possuíam dentes naturais, das quais $125(62,2 \%)$ apresentavam pelo menos 1 dente com cárie radicular. 


\section{2- A Medição da Ocorrência de Cárie de Superfície Radicular}

Em 1980 KATZ publicou um importante artigo, no qual salientava o crescente interesse por parte dos pesquisadores, na época, pela epidemiologia da cárie de superfície radicular, devido às alterações demográficas ocorridas em grande parte do mundo, resultando em um aumento na proporção da população idosa, e aos avanços alcançados no controle da cárie coronária, principalmente nos países desenvolvidos. O Autor fez uma revisão dos métodos utilizados nos 30 anos anteriores para relatar a ocorrência da doença, e observou que: 1) o método mais freqüentemente utilizado, até então, era a proporção de pessoas estudadas exibindo uma ou mais lesões, o qual apresentava como vantagem, além de poder ser usado em estudos de prevalência e incidência, a sua clareza e simplicidade, e como desvantagens, o fato de ignorar a severidade da doença no indivíduo ou na população e não considerar que a quantidade de dentes perdidos pode interferir na medida ; 2) o segundo método seria o número de lesões de cárie radicular por pessoa, o qual já introduz uma medida de severidade e usa a dentição total de um indivíduo como medida de risco, semelhante ao CPO-D; 3) o terceiro método, ou seja, o número de lesões de cárie radicular por dentes presentes apresentava, segundo o Autor, um refinamento ao utilizar apenas os dentes presentes como na situação de risco. Porém, ainda não identificava a verdadeira unidade de risco como denominador. Segundo KATZ , esta unidade de risco seria o número de dentes com recessão gengival. Assim, propôs o Índice de Cárie Radicular (ICR), o qual teria como resultado um grau de ataque de cárie radicular. Por definição, neste caso, cárie radicular seria 
aquela lesão associada à recessão gengival. $\mathrm{O}$ índice pode ser calculado, utilizandose a seguinte fórmula:

$$
\mathbf{I C R}=\frac{\text { sup. cariadas }+ \text { sup. restauradas }}{\text { sup. cariadas }+ \text { sup. restauradas }+ \text { sup. sadias }} \times 100
$$

O ICR, segundo o Autor, representa uma medida que pode ser expressa por dente ou por superfície, bem como por pessoa ou por grupo de dentes.

Apresentando os primeiros resultados obtidos aplicando o ICR, KATZ e col. (1982) publicaram artigo relativo a um estudo realizado com funcionários de uma companhia de seguros americana com idade entre 20 e 64 anos, obtendo um índice de $11,4 \%$ no grupo examinado. Nesta ocasião, os Autores definiram lesões de cárie radicular como lesões moles e progressivas, as quais podiam estar tanto totalmente confinadas à superfície radicular, como envolverem o esmalte adjacente, porém indicando, clinicamente, que a lesão havia se iniciado na superfície radicular.

Em seguida, KATZ (1984) atentou para a necessidade de discussão no sentido de se chegar a um consenso sobre a definição e medida da cárie de superficie radicular, e à forma de relatar os resultados obtidos em estudos nesta área. Em relação ao primeiro problema, o Autor propôs, como critérios táteis-visuais para estudos epidemiológicos, que as lesões de cárie radicular fossem definidas como superfícies com uma aparência escurecida, descolorida ou apresentando uma sensação de superfície pegajosa ou semelhante a couro à sondagem moderada, 
exibindo ou' não cavitação; as lesões escurecidas que não apresentavam sinais de tecido amolecido seriam consideradas inativas. Quanto ao segundo, KATZ observou que existem diferenças entre a sondagem do esmalte e do cemento, sugerindo a necessidade do desenvolvimento de um instrumento específico para o uso em superficie radicular, e que a calibração de examinadores para o exame de cárie radicular deveria buscar, no mínimo, $90 \%$ de concordância intra e inter-examinador. Como opção para o terceiro item, o Autor volta a propor a utilização do Índice de Cárie Radicular (ICR), assumindo, nas conclusões, que "o índice resulta em uma taxa de ataque de lesões de cárie radicular supra-gengivais".

Comentando a apresentação anterior, MUMMA (1984) discordou quando KATZ sugeriu a classificação das lesões em ativas e inativas, no sentido de que este fato introduziria um elemento que poderia comprometer a confiança dos resultados obtidos em estudos epidemiológicos, e compartilhou da opinião de que a exclusão de lesões subgengivais é apropriada, devido, também, à necessidade de garantir a confiabilidade dos resultados.

HUNT e BECK (1985) relataram que as principais dúvidas surgidas em calibrações de examinadores para levantamentos epidemiológicos em populações idosas foram: constatar a presença ou não de recessão gengival, classificar lesões que envolviam múltiplas superfícies, julgar se uma restauração na superfície radicular era devida à cárie ou à abrasão, e se a lesão era originária da superfície radicular ou do esmalte. Neste sentido, os Autores passaram a adotar os seguintes critérios: 1) a recessão gengival seria anotada apenas se a superfície radicular pudesse ser vista 
claramente; 2) uma lesão, restauração ou a recessão gengival seria anotada como envolvendo duas superficies apenas se esta se estendesse por um terço da superfície adjacente; 3) todas as restaurações radiculares seriam anotadas, independente do que as motivaram (cárie ou abrasão) e 4) uma superfície radicular seria anotada como possuindo lesão de cárie se uma lesão ou restauração que envolvesse coroa e raiz tivesse pelo menos metade de sua extensão apical à junção cemento-esmalte.

Dissertando sobre a epidemiologia da cárie radicular, especificamente no que diz respeito à população de risco à doença, BANTING (1986) chamou atenção para o fato de que é importante haver distinção entre perda de inserção e recessão gengival, pois é possivel ocorrer uma situação clínica onde exista perda de inserção e a margem gengival encontra-se acima ou ao nível da junção cemento-esmalte; uma lesão de cárie radicular, neste caso, estaria em nível subgengival. Porém, o Autor destacou que esta situação, no entanto, é relativamente incomum e que a perda de inserção em adultos está normalmente associada à recessão gengival. BANTING concluiu, então, que esta definição de risco tem o efeito de subestimar ligeiramente a prevalência da doença, mas também de facilitar a condução de investigações de larga escala.

Na mesma oportunidade, e na tentativa de colaborar com a padronização de critérios para estudos epidemiológicos sobre a doença, após as críticas levantadas por MUMMA (1984), KATZ (1986) propôs outro critério para classificação das lesões de cárie radicular: 1) lesões ativas ( aquelas com ou sem cavitação, apresentando uma aparência escura e uma sensação de superfície pegajosa ou semelhante a couro à 
sondagem moderada e 2) lesões inativas ( aquelas com cavitação e apresentando uma aparência escura, mas sem sensação de superfície pegajosa ou semelhante a couro à sondagem moderada). No mesmo artigo, o Autor propõe seis convenções para diagnóstico de cárie radicular em pesquisas clínicas, das quais destacam-se a $\mathrm{n}^{\mathrm{o}} 3$ ("para qualquer restauração que se estenda à superfície radicular, o material restaurador deve estender-se por mais de $3 \mathrm{~mm}$ através da junção cemento-esmalte a fim de que a superfície radicular seja anotada como restaurada; exceção se faz às coroas, as quais nunca levam à anotação da superfície radicular como restaurada") e a nº 4 ("todas as lesões de cárie detectadas na superfície radicular deverão ser anotadas como cárie, independente da condição do esmalte adjacente").

DE PAOLA e col. (1989) realizaram um estudo com o objetivo de verificar o efeito, sobre a quantificação da cárie radicular: 1) da classificação da lesão em ativa e inativa; 2) da confusão causada pela presença de superfícies abrasionadas e restauradas e 3) do critério de decisão para proceder em caso de lesões e restaurações envolvendo coroa e raiz. Os Autores concluíram que os critérios de inclusão de diferentes estágios da doença (de lesões incipientes à franca cavitação, passando por lesões inativas e secundárias) influenciam a prevalência da doença; que a inclusão de restaurações provenientes de abrasão ampliam grandemente os resultados, porém seriam necessários mais estudos demonstrando a prevalência desta condição; e que as lesões radiculares originárias da coroa devem ser um componente do ICR. Enfim, que os resultados demonstraram que a prevalência da doença pode variar amplamente, dependendo de como os critérios de diagnóstico são elaborados. 
Considerando a grande discussão sobre os critérios de diagnóstico da cárie radicular que vinha ocorrendo na época, KATZ (1990) publicou outro artigo dissertando sobre o assunto. Em relação à inclusão apenas de lesões ativas ou de lesões inativas conjuntamente, o Autor concluiu que o registro apenas de lesões ativas deveria continuar, até que estudos específicos, demonstrando quantitativamente a necessidade de inclusão das lesões inativas, fossem publicados. Quanto às lesões subgengivais, KATZ defendeu o seu registro como uma entidade à parte: 1) por não haver, até então, instrumento que validasse o seu diagnóstico via sondagem nas condições do exame epidemiológico; 2) devido à forte impressão de que a contribuição deste tipo de lesão seria, percentualmente, de pequena monta e 3) por se considerar tais lesões como uma doença separada, com fatores etiológicos distintos. No mesmo artigo, KATZ acrescentou outras convenções para diagnóstico de cárie radicular, trazendo, como sugestão, o registro de cárie recorrente como uma categoria separada.

A ausência de padronização de critérios de diagnóstico e de forma de relatar a cárie radicular prejudica, segundo BECK (1990), as comparações entre as prevalências observadas nos diversos estudos.

A mesma opinião foi compartilhada por AHERNE e col. (1990) em artigo de revisão, no qual fizeram sugestões quanto à forma de relatar os resultados, propondo tabelas contendo: 1) os níveis de perda dentária, incluindo os níveis de edentulismo na população estudada; 2) a porcentagem de pessoas com pelo menos uma superfície 
radicular afetada por cárie, por idade e sexo; 3) o número médio de dentes afetados por pessoa com o respectivo desvio padrão e 4) o ICR proposto por KATZ (1980).

Em 1993, BECK, ao analisar estudos norte-americanos sobre a epidemiologia da cárie de superfície radicular, tornou a salientar a necessidade de adoção de convenções para o diagnóstico da doença, como as propostas por KATZ (1990), e de convenções de relatórios de pesquisas na área, formulando sugestões, neste sentido, semelhantes à de AHERNE e col. (1990). O Autor destacou, em seu texto, o fato de que é provável que os dados de prevalência sejam substancialmente subestimados devido à alta probabilidade de perda de dentes na idade adulta.

FEJERSKOV e col. (1993) observaram, baseados em estudos escandinavos, que não basta considerar as lesões de cárie radicular em relação à superfícies expostas ao ambiente bucal, ou seja, com recessão gengival, sem se levar em consideração o número de dentes presentes no grupo de pessoas examinadas.

No mesmo ano, BANTING afirmou que a população de risco para cárie radicular deveria incluir todas as raizes com alguma perda de inserção periodontal e salientou que a dúvida sobre a inclusão, ou não, de lesões subgengivais, inativas, descoloridas mas sem cavitação, ainda não havia sido totalmente esclarecida na comunidade científica.

Recentemente, KATZ (1996) publicou uma avaliação da situação do Índice de Cárie Radicular(ICR), proposto 15 anos antes, quanto à sua utilização entre os 
epidemiologistas, bem como às questões concernentes ao índice, debatidas pelos mesmos. O Autor tomou a seguinte posição: 1) recomendou que, enquanto não existisse um método de diagnóstico mais adequado e considerando as lesões de cárie supragengivais e subgengivais como duas entidades distintas em sua etiologia, estas deveriam ser registradas separadamente para propósitos científicos; 2) apesar do cálculo do índice envolver o número de lesões e o número de superfícies em risco, não existe uma relação linear entre os mesmos; 3) o ICR não deve ser a única informação a ser levada em consideração quando da análise dos resultados, sendo que a mesma deve ser realizada utilizando-se dados sobre o número de dentes (por grupo e por idade), o número médio de lesões de cárie e a distribuição por sexo e idade do grupo examinado e 4) a recessão gengival não é um preditor para a cárie radicular, mas um antecedente importante.

Em 1997, a Organização Mundial da Saúde-OMS (WHO,1997) publicou a $4^{\mathrm{a}}$ edição de seu manual para levantamentos epidemiológicos em saúde bucal, o qual trouxe, pela primeira vez, orientações específicas para o registro de cárie de superficie radicular, além do registro de cárie coronária. $\mathrm{O}$ fato exprime uma preocupação de tal órgão com a cárie radicular e assume um papel importante no processo de padronização de critérios para o exame da doença, tão requerido na literatura. Outro aspecto introduzido na nova edição é a observação da quantidade de perda de inserção gengival, o que pode estar relacionada à própria cárie radicular.

Comparando os métodos propostos por KATZ (1980), modificado e complementado em 1986, 1990 e 1996, e pela OMS (WHO,1997), quanto aos 
critérios empregados, observa-se que os mesmos são coincidentes em várias situações, porém existem algumas discrepâncias entre eles. O Quadro 1 resume esta análise.

Quadro 1- Comparação entre os critérios para exame de cárie radicular propostos por KATZ (ICR) e pela Organização Mundial da Saúde (OMS)

\begin{tabular}{|c|c|c|}
\hline Característica & ICR & OMS \\
\hline Unidade & superfície ou dente & dente \\
\hline Instrumento & sonda exploradora & sonda CPI \\
\hline Exposição da Raiz & $\begin{array}{l}\begin{array}{l}\text { superficie além } \\
\text { visível }\end{array} \\
\end{array}$ & $\begin{array}{l}\text { recessão gengival para além } \\
\text { da JCE }\end{array}$ \\
\hline Lesão de Cárie & $\begin{array}{l}\text { lesão amolecida, } \\
\text { escurecida, descolorida, } \\
\text { permitindo fácil penetração } \\
\text { da sonda exploradora }\end{array}$ & $\begin{array}{l}\text { lesão com tecido mole, } \\
\text { detectada após sondagem }\end{array}$ \\
\hline Lesão Subgengival & registrada em separado & não faz menção \\
\hline $\begin{array}{l}\text { Lesões que Envolvem } \\
\text { Coroa e Raiz }\end{array}$ & $\begin{array}{l}\text { considera qualquer lesão } \\
\text { que atinja a raiz próxima à } \\
\text { JCE, independente da } \\
\text { condição do esmalte }\end{array}$ & $\begin{array}{l}\text { considera a raiz cariada se a } \\
\text { lesão se originou na porção } \\
\text { radicular, ou se a raiz } \\
\text { necessita de tratamento em } \\
\text { separado; na dúvida registra } \\
\text { em ambas }\end{array}$ \\
\hline Lesões Recorrentes & $\begin{array}{l}\text { são registradas como uma } \\
\text { categoria específica }\end{array}$ & $\begin{array}{l}\text { não são registradas como } \\
\text { uma categoria específica }\end{array}$ \\
\hline $\begin{array}{l}\text { Restaurações que Envolvem } \\
\text { Coroa e Raiz }\end{array}$ & $\begin{array}{l}\text { a restauração deve estender- } \\
\text { se por mais de } 3 \mathrm{~mm} \text { além } \\
\text { de JCE }\end{array}$ & $\begin{array}{l}\text { a raiz é registrada como } \\
\text { restaurada se este for o local } \\
\text { da lesão primária; na dúvida } \\
\text { registra em ambas }\end{array}$ \\
\hline Coroa Total & $\begin{array}{l}\text { nunca registra a raiz como } \\
\text { restaurada }\end{array}$ & sem critério específico \\
\hline Dente Perdido & $\begin{array}{l}\text { é registrado e considerado } \\
\text { em separado }\end{array}$ & $\begin{array}{l}\text { incluído no cálculo do } \\
\text { Índice CPO-D }\end{array}$ \\
\hline Exclusão Dente/Superfície & $\begin{array}{l}20 \% \text { da área inacessível ao } \\
\text { exame }\end{array}$ & $\begin{array}{l}\text { dente extraído ou que } \\
\text { possui cálculo de modo a } \\
\text { impedir o exame }\end{array}$ \\
\hline Exclusão do Indivíduo & $\begin{array}{l}10 \% \text { das superficies } \\
\text { expostas anotadas como } \\
\text { "ilegíveis" }\end{array}$ & sem critério específico \\
\hline
\end{tabular}


Pode-se observar que há discrepâncias que poderiam interferir na quantificação da ocorrência de cárie de superficie radicular, como as referentes às lesões tratadas ou não, que envolvem coroa e raiz: enquanto para KATZ toda lesão de cárie em superfície radicular próxima à JCE deve ser registrada, independente da condição do esmalte adjacente, para a OMS as lesões de cárie que envolvem coroa e raiz devem promover registro para esta última se esse for o local primário da lesão, se houver dúvida quanto a esta origem ou se a raiz necessitar de tratamento em separado; quanto à presença de restaurações coronárias que se estendem para a raiz, de acordo com KATZ, para se registrar a condição para esta última, esta extensão deve ser maior ou igual a $3 \mathrm{~mm}$, enquanto que a OMS segue o mesmo raciocínio dos casos de lesões não tratadas. Algumas circunstâncias são abordadas apenas por KATZ, como a forma de proceder diante da presença de coroas totais, bem como o critério de exclusão do indivíduo da amostra. Ainda, KATZ propõe o emprego de uma categoria de classificação denominada "cárie radicular recorrente", definida como "lesão de cárie associada com restauração de superfície radicular", enquanto que a OMS enquadra esta situação na categoria "raiz restaurada mas cariada", a qual também inclui as situações de presença de lesões sem associação física com a(s) restauração(ões). 
3-OBJETIVO 
O presente estudo teve como objetivo verificar a concordância entre os resultados obtidos pelo método de exame de cárie de superficie radicular proposto por KATZ (1980), modificado e complementado em 1986, 1990 e 1996, e pela Organização Mundial da Saúde (WHO, 1997). 
4-MATERIAL E MÉTODOS 


\subsection{Treinamento}

Foi realizado um estudo prévio no primeiro semestre de 1999 , no qual os métodos propostos por KATZ (1980), modificado e complementado em 1986, 1990 e 1996, e pela OMS (WHO,1997) foram aplicados pela Autora em um grupo de 38 adultos de 35 a 44 anos, que fizeram parte do Levantamento das Condições de Saúde Bucal do Estado de São Paulo - 1998. Os métodos foram aplicados duas vezes em 20 pessoas desse grupo, tendo sido o erro intra-examinador calculado em 4,5\% para o método proposto pela OMS e 5,1\% para o método por KATZ.

\subsection{População de Estudo}

Foram examinados pacientes de ambos os sexos atendidos nas clínicas das disciplinas de Diagnóstico Clínico e Periodontia da Faculdade de Odontologia de Ribeirão Preto/USP, com idade igual ou superior a 35 anos (faixa etária de maior probabilidade de ocorrência de cárie de superfície radicular). A primeira disciplina foi selecionada pelo grande número de pacientes atendidos em um curto período de tempo e a segunda, por atender pacientes adultos e idosos com dentes naturais presentes na boca em maior número. Ambas têm o atendimento de pacientes estruturado de forma que possibilitava a realização dos exames sem ocasionar grandes transtornos aos pacientes e aos graduandos.

\subsection{Exames}

Os exames bucais para avaliação da ocorrência de cárie de superficie radicular foram realizados pela Autora, de acordo com os métodos propostos por 
KATZ (1980), modificado e complementado em 1986, 1990 e 1996, e pela OMS (WHO,1997), no período de 2 de outubro a 29 de novembro de 1999.

Todos os pacientes atendidos nas referidas clínicas no período relatado, com idade correspondente à faixa etária proposta, foram examinados em duas sessões. $\mathrm{Na}$ primeira, foi aplicado o método proposto pela OMS (WHO,1997). Os pacientes, então, foram agendados para a semana seguinte, quando foi aplicado o método proposto por KATZ (1980), modificado e complementado em 1986, 1990 e 1996. Assim, a cada semana um dos métodos foi aplicado, com o objetivo de diminuir a probabilidade de confusão dos critérios por parte da examinadora. Foram realizados exames em duplicata em 13 pessoas.

\subsection{Condições de Exame}

Os exames foram realizados em cadeira normal, luz natural, com o uso de espelho bucal plano e sonda periodontal preconizada pela OMS. Para aplicação do método proposto por KATZ (1980) modificado e complementado em 1986, 1990 e 1996, foi utilizada sonda exploradora.

\section{5. Índices, Critérios e Registro}

\subsection{1. Índice de Cárie Radicular segundo método proposto pela OMS (WHO,1997).}

Foi utilizada uma ficha elaborada pela autora (Anexo 1) e os seguintes códigos e critérios propostos pela OMS (WHO,1997): 
0- Raiz Hígida: a raiz estava exposta e não havia evidência de cárie ou de restauração (raízes não expostas foram codificadas como "8”).

1- Raiz cariada: lesão que podia ser detectada com a sonda CPI. Se havia comprometimento radicular discreto, produzido por lesão proveniente da coroa, a raiz só era considerada cariada se havia necessidade de tratamento radicular em separado. Para lesões de cárie afetando tanto coroa como raiz, a localização mais provável da lesão primária era considerada como cariada. Quando não era possível avaliar a localização de origem, tanto a coroa quanto a raiz eram registradas nessa condição.

2- Raiz Restaurada mas Cariada: havia uma ou mais restaurações e ao mesmo tempo uma ou mais áreas cariadas, sem fazer distinção entre cárie primária e secundária, ou seja, se as lesões estavam ou não em associação física com a(s) restauração(ões); em situações onde a coroa e raiz estavam envolvidas, a localização mais provável da lesão primária era considerada como restaurada mas cariada; quando não era possível avaliar a localização de origem, tanto a coroa quanto a raiz eram registradas nessa condição.

3- Raiz Restaurada e Sem Cárie. havia uma ou mais restaurações definitivas e inexistia cárie na raiz; em situações onde coroa e raiz estavam envolvidas, a localização mais provável da lesão primária era registrada como restaurada; quando não era possível avaliar a localização de origem, tanto coroa quanto raiz eram registradas como restauradas.

4- Dente Perdido Devido à Cárie: quando um dente havia sido extraído devido à cárie. 
5- Dente Permanente Perdido por Outras Razões: quando um dente estava ausente por razões congênitas, ortodônticas, periodontais ou por trauma.

6- Selante: esta condição era registrada somente para a coroa; a condição da raiz era então avaliada separadamente.

7- Implante: registrava-se este código na casela da raiz, quando da presença de um implante.

8- Raiz não Exposta: não havia exposição da superfície radicular, isto é, não havia retração gengival para além da junção cemento-esmalte.

9- Dente Excluído: indicava um dente no qual o cálculo estava presente em uma extensão que impossibilitava o exame.

Obs: para os códigos "4" e "5" não foi levada em consideração a orientação da OMS de registrar a raiz com código "7" ou "9", dado que não tinha relevância para este estudo; o código "9" foi utilizado somente quando a raiz não pôde ser examinada.

\subsection{2. Índice de Cárie Radicular (ICR) segundo método proposto por KATZ} (1980), modificado e complementado em 1986, 1990 e 1996

O Índice de Cárie Radicular (ICR), proposto por KATZ (1980), expressa a proporção de superfícies radiculares cariadas e restauradas entre as superfícies radiculares expostas ao ambiente bucal, ou seja, com recessão gengival. 
O Índice de Cárie Radicular é obtido pela seguinte fórmula:

ICR $=\frac{\text { sup. cariadas }+ \text { sup. restauradas }}{\text { sup. cariadas }+ \text { sup. restauradas }+ \text { sup. sadias }} \times 100$

Foi utilizada uma ficha proposta pela autora, como consta no Anexo 2 e os seguintes critérios:

A- Uma superfície radicular foi considerada como possuindo recessão gengival quando, segundo KATZ (1996), a superfície apical à junção cemento-esmalte estivesse visível.

B- Uma superfície radicular foi considerada como cariada quando, segundo KATZ (1986) apresentava uma área com aparência escurecida, descolorida, bem definida e amolecida, permitindo fácil penetração da sonda exploradora.

C- Uma superfície radicular foi registrada como restaurada quando possuísse uma restauração, sem que , como coloca BECK e col. (1985), se julgasse se esta era resultado de abrasão, erosão ou cárie.

D- Foram adotadas as convenções para diagnóstico propostas por KATZ $(1986,1990)$, a seguir:

nº 1- Se o diagnóstico de Cárie ou Restauração fosse "incerto", registrava-se a face como sadia. 
n²- Toda cárie detectada em superfícies radiculares próxima à junção cementoesmalte (JCE) era registrada como cariada, independente da condição do esmalte adjacente.

n 3- No caso de restauração coronária que se estendesse para a superfície radicular, a mesma deveria se estender por mais de $3 \mathrm{~mm}$ além da JCE para se registrar a superficie radicular como restaurada. [Exceção: coroas totais extensivas à superficie radicular nunca eram anotadas como restauradas para a superfície radicular].

nº- Para que uma restauração fosse anotada como envolvendo múltiplas superfícies, a restauração deveria estender-se por pelo menos $1 / 3$ das superfícies adjacentes.

n5a- Cárie recorrente associada com restauração de superfície radicular era registrada como "cárie radicular recorrente".

nº 5 b- Cárie recorrente associada com uma restauração coronária ou uma coroa total era registrada como "cárie radicular contígua com restauração coronária".

n6- Para qualquer superficie radicular que estivesse cariada, o evento de uma cárie radicular adicional porém separada, deveria ser registrada como "lesão de cárie radicular adicional".

[Nota: para as convenções 5a, 5b e 6, a análise primária dos dados deve incorporá-las na categoria Cárie (com cariada tendo precedência sobre restaurada, em regra) e uma análise secundária dos dados que relate com mais detalhes as categorias de cárie é recomendada.] 
$\mathrm{n}^{\circ} 7$ - Qualquer superfície radicular que aparentasse estar sadia mas que possuísse mais de $20 \%$ de sua área inacessível para o exame, devido ao cálculo e/ou depósitos de placa consistente, era registrada como "ilegivel".

$\mathrm{n}^{\circ} 8$ - Qualquer pessoa com mais de $10 \%$ de suas superficies radiculares com risco (com recessão gengival) anotadas como "ilegíveis" era eliminada do estudo.

Os códigos utilizados, no presente estudo, para o Índice de Cárie Radicular foram os seguintes:

0- dente perdido

1- superfície radicular sem recessão gengival

2- superficie radicular com recessão gengival e cariada

3- superfície radicular com recessão gengival e restaurada

4- superfície radicular com recessão gengival e sadia

5- superfície radicular com recessão gengival e com cárie recorrente

6- superficie radicular com recessão gengival e com cárie contígua a restauração coronária

7- superfície radicular com recessão gengival e com lesões de cárie adicionais

8- lesão subgengival (detectada através de sondagem)

9- superficie "ilegível"

\subsection{Análise dos Resultados}

4.6.1. O Índice de Cárie Radicular (ICR) foi calculado para os grupos de dentes e superfícies, utilizando-se a somatória das anotações de lesões de cárie radicular, 
dividida pela somatória das anotações de recessão gengival, multiplicado por 100, e foi chamado de ICR médio para o grupo de pessoas examinadas e calculado utilizando-se a média dos valores do ICR individual.

4.6.2. A concordância entre os métodos foi analisada utilizando-se a estatística Kappa, proposta por COHEN (1960), que aplica a seguinte fórmula:

$$
k=\frac{\mathrm{P}_{\mathrm{o}}-\mathrm{P}_{\mathrm{e}}}{1-\mathrm{P}_{\mathrm{e}}}
$$

onde:

$\mathrm{P}_{\mathrm{o}}=$ proporção de concordância observada, obtida pelo $\mathrm{n}^{\circ}$ de dentes sadios observados por ambos os métodos $+\mathrm{n}^{\circ}$ de dentes com lesões de cárie observados por ambos os métodos;

$\mathrm{P}_{\mathrm{e}}=$ proporção de concordância esperada, obtida pelo $\mathrm{n}^{\circ}$ de dentes sadios observados no método $a \times \mathrm{n}^{\circ}$ de dentes sadios observados $\mathrm{n}^{\circ}$ método $b+\mathrm{n}^{\circ}$ de dentes com lesões de cárie observados pelo método $a \mathrm{x} \mathrm{n}^{\circ}$ de dentes com lesões de cárie observados no método $b$, dividido pelo $\mathrm{n}^{\circ}$ de dentes examinados ao quadrado.

Foram também calculados o Coeficiente de Correlação de Pearson (r) e feito o teste de diferença de duas médias t- Student pareado (BERQUÓ e col. , 1981).

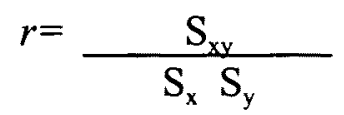

onde:

$\mathrm{S}_{\mathrm{xy}}=$ covariância entre $\mathrm{x}$ e $\mathrm{y}$;

$\mathrm{S}_{\mathrm{x}}=$ desvio padrão de $\mathrm{x}$;

$S_{y}=$ desvio padrão de $y$; 


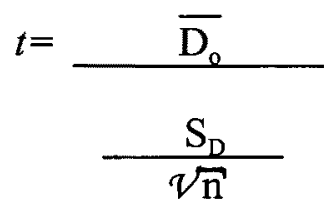

onde:

$\overline{\mathrm{D}_{\mathrm{o}}}=$ diferença média entre os métodos;

$S_{D}=$ desvio padrão da diferença entre os métodos;

$\mathrm{n}=$ tamanho da amostra.

Para tanto, foram utilizados os programas para computador EPI INFO versão 5.01 (Centers for Disease Control / World Health Organization, 1991) e EPIDAT versão 1.0 (Servicio Galego de Saúde, 1994).

4.6.3. Os valores obtidos do Kappa foram classificados (conforme apresentado por PEREIRA, 1995), de acordo com o Quadro 2.

Quadro 2- Classificação da concordância, segundo valores do Kappa.

\begin{tabular}{|cc|}
\hline KAPPA & Concordância \\
$<0,00$ & ruim \\
$0,00-0,20$ & fraca \\
$0,21-0,40$ & sofrivel \\
$0,41-0,60$ & regular \\
$0,61-0,80$ & boa \\
$0,81-0,99$ & ótima \\
1,00 & perfeita \\
\hline
\end{tabular}


5-RESULTADOS 
Foram examinados 67 pacientes entre 36 e 78 anos, com idade média de 47,87 anos (desvio padrão $=9,51$ anos), sendo $71,6 \%$ do sexo feminino, conforme se observa na Tabela 1.

Tabela 1 - Distribuição do número e da porcentagem de pessoas segundo a faixa etária e o sexo.

\begin{tabular}{|c|c|c|c|c|c|c|}
\hline \multirow{3}{*}{$\begin{array}{c}\text { FAIXA ETÁRIA } \\
\text { (anos) }\end{array}$} & \multicolumn{4}{|c|}{ SEXO } & & \\
\hline & \multicolumn{2}{|c|}{ MASCULINO } & \multicolumn{2}{|c|}{ FEMININO } & \multicolumn{2}{|c|}{ TOTAL } \\
\hline & $\mathbf{N}^{0}$ & $\%$ & $\mathbf{N}^{0}$ & $\%$ & $\mathbf{N}^{0}$ & $\%$ \\
\hline 35 a 39 & 4 & 23,5 & 13 & 76,5 & 17 & 100,0 \\
\hline 40 a 44 & 5 & 29,4 & 12 & 70,6 & 17 & 100,0 \\
\hline 45 a 49 & 1 & 11,1 & 8 & 88,9 & 9 & 100,0 \\
\hline 50 a 54 & 2 & 18,2 & 9 & 81,8 & 11 & 100,0 \\
\hline 55 a 59 & 3 & 60,0 & 2 & 40,0 & 5 & 100,0 \\
\hline 60 a 64 & 2 & 40,0 & 3 & 60,0 & 5 & 100,0 \\
\hline 65 a 69 & 1 & 50,0 & 1 & 50,0 & 2 & 100,0 \\
\hline 70 a 74 & - & - & - & - & - & 100,0 \\
\hline 75 a 79 & 1 & 100,0 & - & - & 1 & 100,0 \\
\hline Total & 19 & 28,4 & $\overline{48}$ & 71,6 & 67 & 100,0 \\
\hline
\end{tabular}

Nota-se, ainda, que $50,7 \%(n=34)$ possuíam idade entre 35 e 44 anos, grupo etário recomendado pela OMS (WHO,1997) para acompanhamento das condições de saúde bucal dos adultos.

Foram realizados 13 exames em duplicata (19,4\% da população de estudo), nos quais o erro intra-examinador foi de $4,4 \%$ para o método proposto por KATZ (1980), modificado e complementado em 1986, 1990 e 1996, e de 3,5\% para o método proposto pela OMS (WHO,1997). 


\subsection{Ocorrência de Cárie de Superfície Radicular segundo KATZ (1980),} modificado e complementado em 1986, 1990, 1996

Os pacientes examinados apresentaram, em média, 21,19 dentes presentes na boca (desvio padrão $=5,97$ dentes). Entre estes, $26,4 \%$ das superficies apresentavam recessão gengival.

$\mathrm{Na}$ Tabela 2 está apresentada a distribuição das pessoas examinadas de acordo com o número de dentes com experiência de cárie de superfície radicular.

Tabela 2 - Distribuição do número e da porcentagem de pessoas segundo o número de dentes com lesão de cárie de superfície radicular, de acordo com o método proposto por KATZ (1980), modificado e complementado em 1986, 1990 e 1996.

\begin{tabular}{ccc}
\hline $\begin{array}{c}\text { DENTES COM LESÃO DE } \\
\text { CÁRIE DE SUPERFÍCIE } \\
\text { RADICULAR }\end{array}$ & $\mathbf{N}^{\mathbf{o}}$ & $\%$ \\
\hline 0 & 24 & 35,8 \\
1 & 14 & 20,9 \\
2 & 10 & 14,9 \\
3 & 7 & 10,4 \\
4 & 5 & 7,5 \\
5 & 2 & 3,0 \\
6 & 1 & 1,5 \\
7 & 1 & 1,5 \\
8 & 1 & 1,5 \\
12 & 1 & 1,5 \\
13 & 1 & 1,5 \\
\hline TOTAL & 67 & 100,0 \\
\hline
\end{tabular}

Nota-se que $35,8 \%(n=24)$ das pessoas examinadas não apresentavam lesão de cárie de superfície radicular, e 64,2\% $(n=43)$ possuíam entre 1 e 13 dentes com lesão da doença. O número médio de dentes com lesão de cárie de superfície 
radicular por pessoa da população de estudo, segundo este método, foi 1,96 (desvio padrão=2,62).

$\mathrm{Na}$ Tabela 3 é apresentada a distribuição das pessoas examinadas segundo o Índice de Cárie Radicular (ICR).

Tabela 3 - Distribuição do número e da porcentagem de pessoas examinadas segundo o Índice de Cárie Radicular - ICR (\%).

\begin{tabular}{ccc}
\hline ICR & $\mathbf{N}^{\mathbf{0}}$ & $\%$ \\
\hline 1a 5 & 24 & 35,8 \\
6 a 10 & 1 & 1,5 \\
11 a 15 & 10 & 14,9 \\
16 a 20 & 4 & 6,0 \\
21 a 25 & 8 & 11,9 \\
26 a 30 & 6 & 8,9 \\
31 a 35 & 3 & 4,5 \\
36 a 40 & 3 & 4,5 \\
41 a 45 & - & - \\
46 a 50 & 3 & 4,5 \\
51 a 55 & - & - \\
56 a 60 & 1 & 1,5 \\
61 a 65 & 2 & 3,0 \\
66 a 70 & - & - \\
71 a 75 & - & - \\
76 a 80 & - & - \\
81 a 85 & - & - \\
86 a 90 & - & - \\
91 a 95 & 1 & 1,5 \\
96 a 100 & - & - \\
TOTAL & 1 & 1,5 \\
\hline
\end{tabular}

Pode-se observar que $52,2 \%(n=35)$ das pessoas examinadas apresentaram ICR máximo de 10,0\%. O Índice de Cárie Radicular médio na população de estudo foi $16,21 \%$ (desvio padrão $=20,60 \% ; \mathrm{IC}_{95 \%}=11,28 \% \vdash 21,14 \%$ ). 
Na Tabela 4 é apresentada a condição da raiz nos dentes e superfícies presentes na boca.

Tabela 4 - Distribuição de dentes e superfícies (valores absolutos, proporção e número médio por pessoa), segundo a condição da raiz, de acordo com o método proposto por KATZ (1980), modificado e complementado em 1986,1990 e 1996.

\begin{tabular}{|c|c|c|c|c|c|c|}
\hline \multirow[t]{2}{*}{ CONDIÇÃ̃ ${ }^{*}$} & \multicolumn{3}{|c|}{ DENTE } & \multicolumn{3}{|c|}{ SUPERFÍCIE } \\
\hline & $\mathrm{N}^{0}$ & $\%$ & Média & $\mathrm{N}^{\mathrm{o}}$ & $\%$ & Média \\
\hline Com Recessão Gengival & 779 & 54,8 & 11,63 & 1498 & 26,3 & 22,36 \\
\hline Sem Recessão Gengival & 637 & 44,8 & 9,51 & 4155 & 73,0 & 62,01 \\
\hline Excluído (a) & 6 & 0,4 & 0,09 & 35 & 0,7 & 0,43 \\
\hline Total & 1422 & 100,0 & n.a. & 5688 & 100,0 & n.a. \\
\hline
\end{tabular}

Entre os dentes presentes, $54,8 \%(n=779)$ apresentavam recessão gengival; desses, $83,2 \%(n=648)$ apresentavam as superficies radiculares hígidas e $16,8 \%$ $(n=131)$ com lesão de cárie; destes últimos, 51,2\% $(n=67)$ não estavam tratados. Quanto às superficies, 26,3\% (n=1498) encontravam-se expostas ao ambiente bucal. Entre elas, $89,9 \%(n=1346)$ estavam hígidas. Em relação às superficies com lesão de cárie radicular $(n=152), 51,3 \%(n=78)$ necessitavam de tratamento.

Pôde-se observar que os pacientes possuíam, em média, 1,96 dentes e 2,27 superfícies com lesão de cárie de superfície radicular. 
Na Figura 1 é apresentado o ICR para os diversos grupos de dentes.

Figura 1- Índice de Cárie Radicular (ICR) segundo grupos de dentes por arcadas.

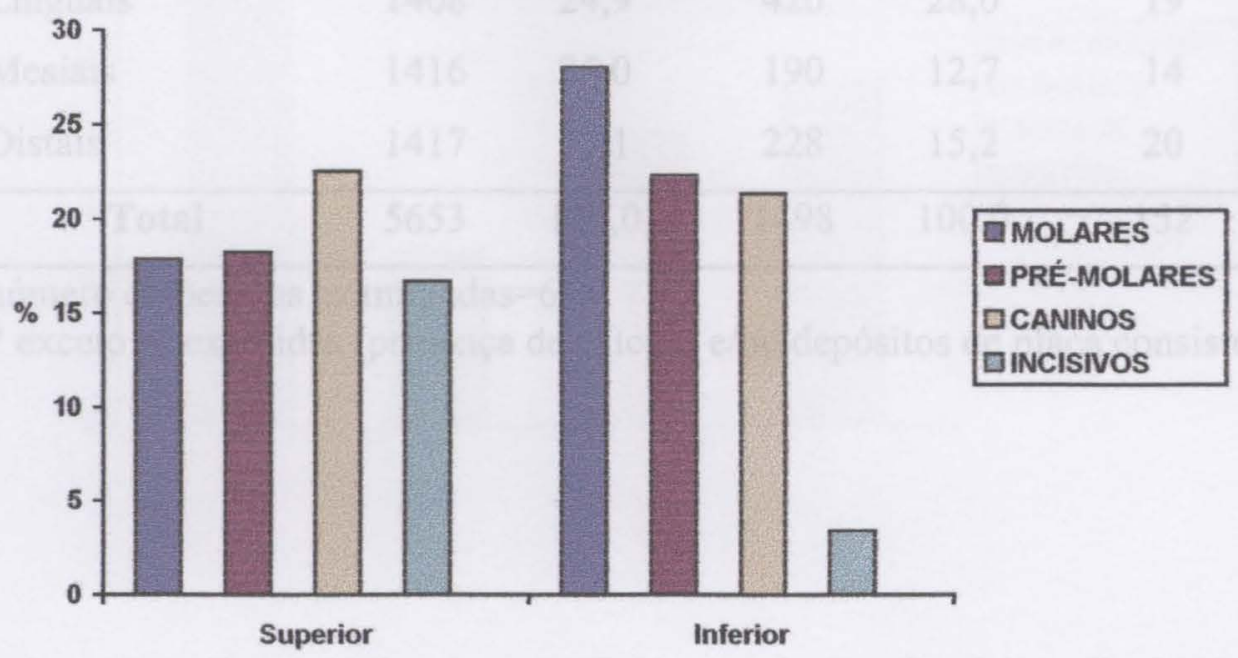

Pode-se observar que os maiores valores para o ICR foram encontrados nos molares inferiores $(28,07 \%)$, seguidos dos caninos superiores $(22,5 \%)$ e pré-molares e caninos inferiores $(22,3 \%$ e $21,3 \%$, respectivamente). Ainda, os menores valores para o índice foram observados nos incisivos inferiores $(3,4 \%)$.

Na Tabela 5 é apresentada a distribuição de superfícies radiculares apresentando recessão gengival e atacadas por cárie. 
Tabela 5 - Número e proporção de superfícies radiculares examinadas segundo localização e presença de recessão gengival e lesões de cárie radicular, de acordo com o método proposto por KATZ (1980), modificado e complementado em 1986, 1990 e 1996.

\begin{tabular}{|c|c|c|c|c|c|c|}
\hline \multirow[t]{2}{*}{ LOCALIZAÇÃO } & \multicolumn{2}{|c|}{ EXAMINADAS* } & \multicolumn{2}{|c|}{$\begin{array}{c}\text { COM } \\
\text { RECESSÃO } \\
\text { GENGIVAL }\end{array}$} & \multicolumn{2}{|c|}{$\begin{array}{l}\text { COM LESÕES } \\
\text { DE CÁRIE }\end{array}$} \\
\hline & $\mathrm{N}^{0}$ & $\%$ & $\mathrm{~N}^{\circ}$ & $\%$ & $\mathrm{~N}^{0}$ & $\%$ \\
\hline Vestibulares & 1412 & 25,0 & 660 & 44,1 & 99 & 65,1 \\
\hline Linguais & 1408 & 24,9 & 420 & 28,0 & 19 & 12,5 \\
\hline Mesiais & 1416 & 25,0 & 190 & 12,7 & 14 & 9,2 \\
\hline Distais & 1417 & 25,1 & 228 & 15,2 & 20 & 13,2 \\
\hline Total & 5653 & 100,0 & 1498 & 100,0 & 152 & 100,0 \\
\hline
\end{tabular}

número de pessoas examinadas $=67$

* exceto as excluídas (presença de cálculo e/ou depósitos de placa consistente)

Os valores médios de superfícies com lesões de cárie radicular e o ICR por superfícies dos dentes são mostrados nas Figuras 2 e 3, respectivamente.

Figura 2 - Numero medio de superficies radiculares atacadas por carie por pessoa segundo localizacao

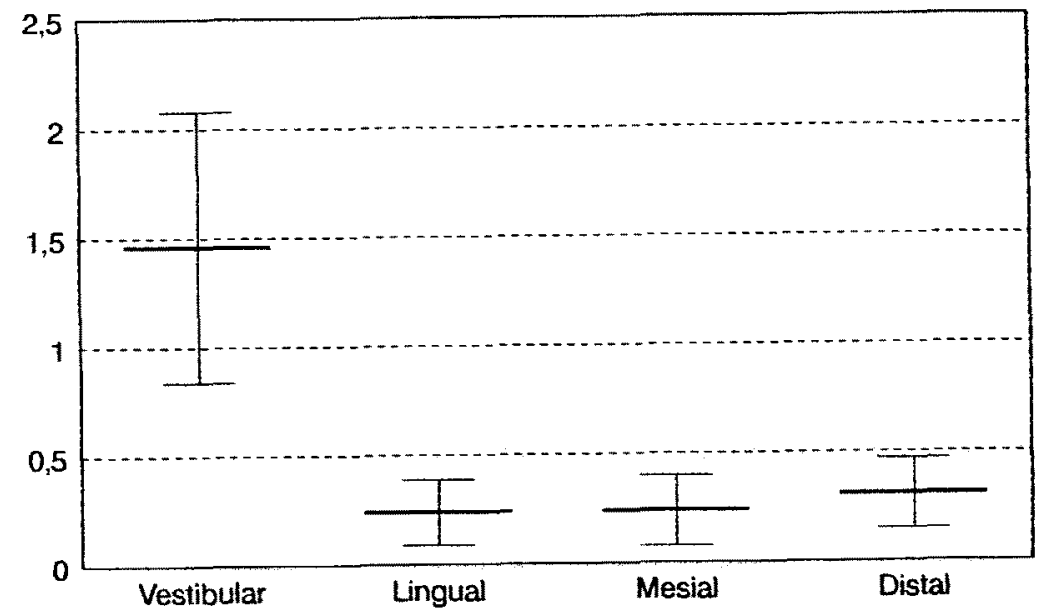


Figura 3-Índice de Cárie Radicular por superfíces, segundo

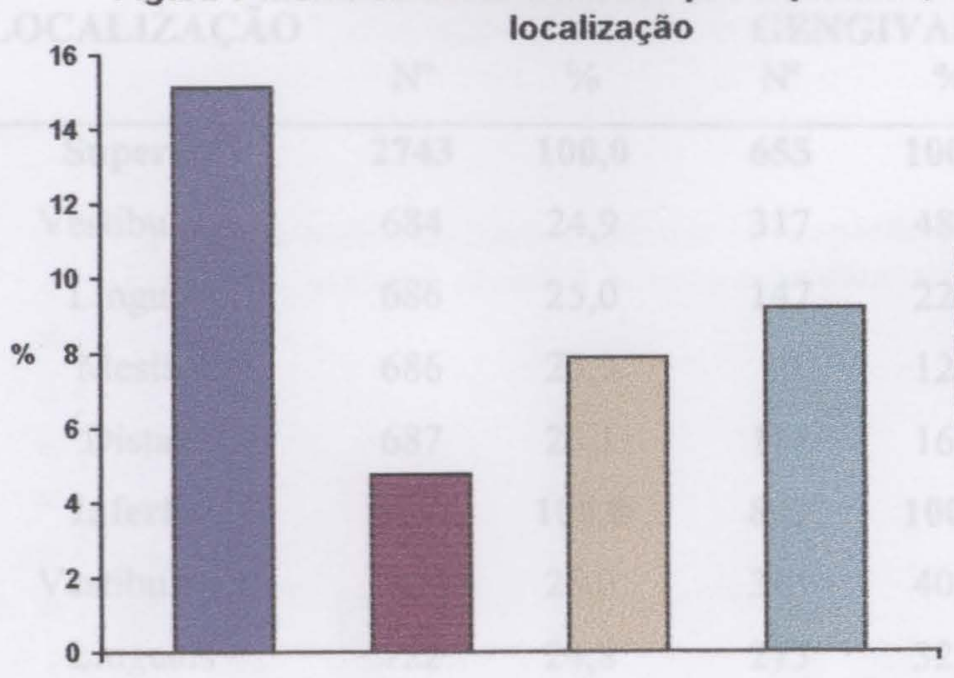

IDISTAIS

Observa-se que os valores absolutos, bem como o número médio de superficies radiculares atacadas por cárie (Tabela 4 e Figura 2) foram maiores nas superficies vestibulares (100 e 1,49 respectivamente), seguidas pelas distais (21 e 0,31 respectivamente), linguais ou palatinas (20 e 0,30 respectivamente) e mesiais (15 e 0,22 respectivamente), e o ICR (Figura 3) foi maior nas superficies vestibulares $(15,13 \%)$, seguidas das distais $(9,17 \%)$, mesiais $(7,85 \%)$ e linguais $(4,75 \%)$.

A distribuição da doença nas superfícies de acordo com as arcadas está apresentada na Tabela 6 e os valores médios na Figura 4. 
Tabela 6 - Número e proporção de superfícies radiculares examinadas segundo localização e presença de recessão gengival e lesões de cárie radicular nas arcadas da boca, de acordo com o método proposto por KATZ (1980), modificado e complementado em 1986, 1990 e 1996.

\begin{tabular}{|c|c|c|c|c|c|c|}
\hline \multirow[t]{2}{*}{ LOCALIZAÇĀO } & \multicolumn{2}{|c|}{ EXAMINADAS* } & \multicolumn{2}{|c|}{$\begin{array}{c}\text { COM } \\
\text { RECESSÃO } \\
\text { GENGIVAL }\end{array}$} & \multicolumn{2}{|c|}{$\begin{array}{l}\text { COM LESÕES } \\
\text { DE CÁRIE }\end{array}$} \\
\hline & $\mathrm{N}^{\mathrm{o}}$ & $\%$ & $\mathrm{~N}^{\mathrm{o}}$ & $\%$ & $\mathrm{~N}^{\circ}$ & $\%$ \\
\hline Superior & 2743 & 100,0 & 655 & 100,0 & 76 & 100,0 \\
\hline Vestibulares & 684 & 24,9 & 317 & 48,5 & 38 & 50,0 \\
\hline Linguais & 686 & 25,0 & 147 & 22,4 & 14 & 18,4 \\
\hline Mesiais & 686 & 25,0 & 80 & 12,2 & 13 & 17,1 \\
\hline Distais & 687 & 25,1 & 111 & 16,9 & 11 & 14,5 \\
\hline Inferior & 2910 & 100,0 & 843 & 100,0 & 86 & 100,0 \\
\hline Vestibulares & 728 & 25,0 & 343 & 40,7 & 61 & 70,9 \\
\hline Linguais & 722 & 24,8 & 273 & 32,4 & 5 & 5,8 \\
\hline Mesiais & 730 & 25,1 & 110 & 13,0 & 1 & 1,2 \\
\hline Distais & 730 & 25,1 & 117 & 13,9 & 19 & 22,1 \\
\hline
\end{tabular}

número de pessoas examinadas $=67$

* exceto as excluídas (presença de cálculo e/ou depósitos de placa consistente)

Figura 4 - Numero medio de superticies radiculares atacadas por carie por pessoa

segundo localizacao e arcadas da boca

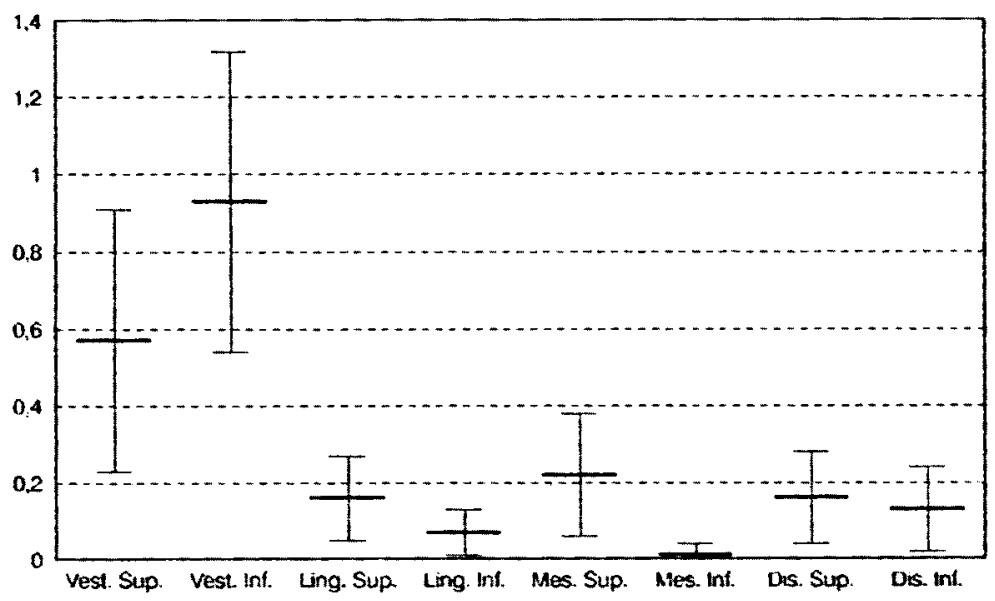

Pode-se notar que as superficies que apresentaram os maiores valores absolutos e médios de lesões radiculares foram as vestibulares inferiores $(0,93)$ e 
superiores $(0,57)$, seguidas pelas linguais superiores $(0,20)$ e mesiais superiores $(0,21)$, sendo o menor, o das mesiais inferiores $(0,01)$.

Na Figura 5 está apresentada a distribuição do ICR nas superfícies dos dentes.

Figura 5- Índice de Cárie Radicular em superfícies dentais, segundo arcadas da boca e localizaçao.

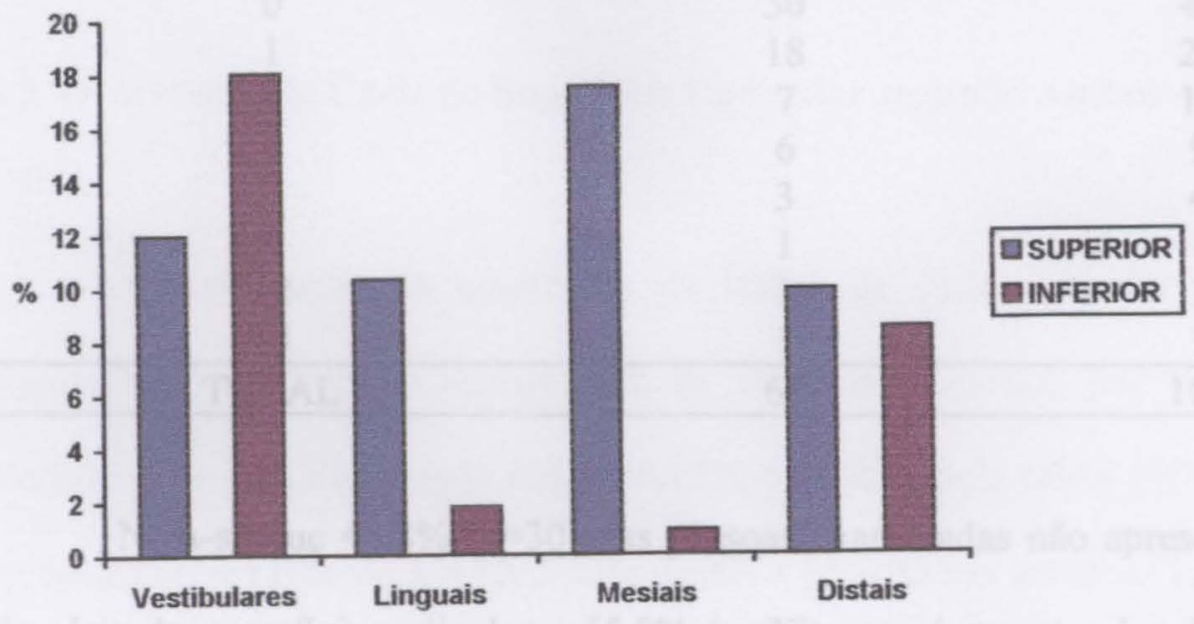

Quanto ao ICR, o maior valor foi observado nas superfícies vestibulares inferiores $(18,0 \%)$ seguidas das mesiais superiores $(17,5 \%)$ e vestibulares superiores $(12,0 \%)$ e o menor, nas mesiais inferiores $(0,9 \%)$.

\subsection{Ocorrência de Cárie de Superfície Radicular segundo a OMS (WHO,1997)}

Considerando-se o método de avaliação de cárie de superfície radicular proposto pela OMS (WHO,1997), os pacientes examinados apresentaram, em média, 21,10 dentes presentes na boca (desvio padrão $=5,95$ dentes). Na Tabela 6 está 
apresentada a distribuição das pessoas examinadas de acordo com o número de dentes com experiência de cárie de superfície radicular.

Tabela 7 - Distribuição do número e da porcentagem de pessoas segundo o número de dentes com lesão de cárie de superfície radicular, de acordo com o método proposto pela OMS (WHO,1997).

\begin{tabular}{ccc}
\hline $\begin{array}{c}\text { DENTES COM LESÃO DE } \\
\text { CÁRIE DE SUPERFICIE } \\
\text { RADICULAR }\end{array}$ & No. & $\%$ \\
\hline 0 & 30 & 44,8 \\
1 & 18 & 26,8 \\
2 & 7 & 10,4 \\
3 & 6 & 9,0 \\
5 & 3 & 4,5 \\
6 & 1 & 1,5 \\
12 & 1 & 1,5 \\
13 & 1 & 1,5 \\
\hline TOTAL & 67 & 100,0 \\
\hline
\end{tabular}

Nota-se que $44,8 \%(n=30)$ das pessoas examinadas não apresentavam lesão de cárie de superfície radicular e 55,2\% $(n=37)$ possuíam entre 1 e 13 dentes com lesão da doença. $\mathrm{O}$ número médio de dentes com lesão de cárie de superfície radicular observado na população de estudo, segundo este método, foi 1,43 (desvio padrão=2,42).

Tabela 8 - Distribuição de dentes (valores absolutos, proporção e número médio por pessoa), segundo a condição da raiz, de acordo com o método proposto pela OMS (WHO,1997).

\begin{tabular}{cccc}
\hline \multirow{2}{*}{ CONDIÇÃO * } & \multicolumn{3}{c}{ DENTE } \\
\cline { 2 - 4 } & $\mathrm{N}^{\circ}$ & $\%$ & Média \\
\hline Com Recessão Gengival & 814 & 57,2 & 12,15 \\
Sem Recessão Gengival & 605 & 42,5 & 9,03 \\
Excluído (a) & 4 & 0,3 & 0,06 \\
\hline Total & 1423 & 100,0 & n.a. \\
\hline
\end{tabular}

número de pessoas examinadas $=67$

* observada nos dentes presentes 
n.a. : não se aplica

Pôde-se notar que $57,2 \%(n=814)$ dos dentes presentes apresentavam superfícies radiculares com recessão gengival. Em 88,2\% $(n=718)$ deles, as superfícies radiculares expostas apresentavam-se hígidas e $11,8 \%(\mathrm{n}=96)$ com lesões de cárie. Entre estas últimas, 57,3\% $(n=55)$ representavam lesões de cárie de superficie radicular não tratadas.

\subsection{Ocorrência de Cárie de Superfície Radicular segundo Ambos os Métodos}

A distribuição da ocorrência de lesões de cárie radicular observada na população de estudo de acordo com os critérios propostos por KATZ (1980), modificado e complementado em 1986,1990 e 1996, e pela OMS (WHO,1997) está apresentada, em relação aos grupos de dentes e posição nas arcadas (Tabelas 9 - 24), em relação aos quadrantes da boca (Tabelas 25 - 28), em relação às arcadas da boca (Tabelas 29 e 30), em relação aos lados da boca (Tabelas 31 e 32) e para a boca como um todo (Tabela 33).

\subsubsection{Concordância Segundo Grupo de Dentes}

Tabela 9 - Número de molares superiores direitos de pacientes adultos segundo presença de cárie de superfície radicular (tratada ou não) de acordo com critérios propostos por KATZ (1980), modificado e complementado em 1986, 1990 e 1996, e pela OMS (WHO,1997).

\begin{tabular}{|c|c|c|c|}
\hline \multirow[t]{2}{*}{ OMS } & \multicolumn{2}{|c|}{ KATZ } & \multirow[t]{2}{*}{ TOTAL } \\
\hline & PRESENCA & AUSENCIA & \\
\hline PRESENÇA & 9 & 1 & 10 \\
\hline AUSÊNCIA & 2 & 90 & 92 \\
\hline TOTAL & 11 & 91 & 102 \\
\hline
\end{tabular}

Kappa $=0,841 ;$ concordância ótima; $\mathrm{p}<0,01$ 
Observa-se que nos molares superiores direitos houve uma lesão de cárie de superficie radicular, detectada pelo método proposto pela OMS, e que não foi detectada segundo critérios propostos por KATZ. O inverso também ocorreu em dois casos, sendo que a concordância entre ambos foi considerada ótima.

Tabela 10 - Número de molares superiores esquerdos de pacientes adultos segundo presença de cárie de superfície radicular (tratada ou não) de acordo com critérios propostos por KATZ (1980), modificado e complementado em 1986, 1990 e 1996, e pela OMS (WHO,1997).

\begin{tabular}{|c|c|c|c|}
\hline \multirow[t]{2}{*}{ OMS } & \multicolumn{2}{|c|}{ KATZ } & \multirow[t]{2}{*}{ TOTAL } \\
\hline & PRESENÇA & AUSÊNCIA & \\
\hline PRESENÇA & 6 & - & 6 \\
\hline AUSÊNCIA & 5 & 82 & 87 \\
\hline TOTAL & 11 & 82 & 93 \\
\hline
\end{tabular}

Kappa $=0,679$; concordância boa; $p<0,01$

Já em relação aos molares superiores esquerdos, a concordância foi considerada boa, com um número maior de lesões detectadas pelo método proposto por KATZ.

Tabela 11 - Número de pré-molares superiores direitos de pacientes adultos segundo presença de cárie de superficie radicular (tratada ou não) de acordo com critérios propostos por KATZ (1980), modificado e complementado em 1986, 1990 e 1996, e pela OMS (WHO,1997).

\begin{tabular}{|c|c|c|c|}
\hline \multirow[t]{2}{*}{ OMS } & \multicolumn{2}{|c|}{ KATZ } & \multirow[t]{2}{*}{ TOTAL } \\
\hline & PRESENCA & AUSÊNCIA & \\
\hline PRESENÇA & 5 & - & 5 \\
\hline AUSÊNCIA & 4 & 81 & 85 \\
\hline TOTAL & 9 & 81 & 90 \\
\hline
\end{tabular}

Kappa $=0,692 ;$ concordância boa; $\mathrm{p}<0,01$

No caso dos pré-molares superiores direitos, observa-se que não foram detectadas lesões somente pelo método proposto pela OMS, enquanto que 4 lesões 
foram detectadas somente pelo método proposto por KATZ. Ainda assim, a concordância foi considerada boa.

Tabela 12 - Número de pré-molares superiores esquerdos de pacientes adultos segundo presença de cárie de superfície radicular (tratada ou não) de acordo com critérios propostos por KATZ (1980), modificado e complementado em 1986, 1990 e 1996, e pela OMS (WHO,1997).

\begin{tabular}{|c|c|c|c|}
\hline \multirow[t]{2}{*}{ OMS } & \multicolumn{2}{|c|}{ KATZ } & \multirow[t]{2}{*}{ TOTAL } \\
\hline & PRESENÇA & AUSÊNCIA & \\
\hline PRESENÇA & 7 & - & 7 \\
\hline AUSÊNCIA & 5 & 82 & 87 \\
\hline TOTAL & 12 & 82 & 94 \\
\hline
\end{tabular}

Kappa $=0,709$; concordância boa; $p<0,01$

De forma semelhante aos pré-molares superiores direitos, no caso dos prémolares superiores esquerdos houve 5 casos de lesões detectadas somente pelo método proposto por KATZ, o que também levou a uma concordância boa.

Tabela 13 - Número de caninos superiores direitos de pacientes adultos segundo presença de cárie de superfície radicular (tratada ou não) de acordo com critérios propostos por KATZ (1980), modificado e complementado em 1986, 1990 e 1996, e pela OMS (WHO,1997).

\begin{tabular}{|c|c|c|c|}
\hline \multirow[t]{2}{*}{ OMS } & \multicolumn{2}{|c|}{ KATZ } & \multirow[t]{2}{*}{ TOTAL } \\
\hline & PRESENÇA & AUSENNCIA & \\
\hline PRESENÇA & 3 & - & 3 \\
\hline AUSÊNCIA & 1 & 51 & 52 \\
\hline TOTAL & 4 & 51 & 55 \\
\hline
\end{tabular}

Kappa $=0,847$; concordância ótima; $p<0,01$

A Tabela 13 mostra que houve apenas uma discordância entre ambos os métodos, lesão esta detectada pelo método proposto por KATZ, o que levou a uma 
concordância considerada ótima. A mesma situação foi observada com os caninos superiores esquerdos (Tabela 14).

Tabela 14 - Número de caninos superiores esquerdos de pacientes adultos segundo presença de cárie de superfície radicular (tratada ou não) de acordo com critérios propostos por KATZ (1980), modificado e complementado em 1986, 1990 e 1996, e pela OMS (WHO, 1997).

\begin{tabular}{|c|c|c|c|}
\hline \multirow[t]{2}{*}{ OMS } & \multicolumn{2}{|c|}{ KATZ } & \multirow[t]{2}{*}{ TOTAL } \\
\hline & PRESENÇA & AUSÊNCIA & \\
\hline PRESENÇA & 4 & - & 4 \\
\hline AUSÊNCIA & 1 & 50 & 51 \\
\hline TOTAL & 5 & 50 & 55 \\
\hline
\end{tabular}

Kappa $=0,879 ;$ concordância ótima; $p<0,01$

Tabela 15 - Número de incisivos superiores direitos de pacientes adultos segundo presença de cárie de superfície radicular (tratada ou não) de acordo com critérios propostos por KATZ (1980), modificado e complementado em 1986, 1990 e 1996, e pela OMS (WHO,1997).

\begin{tabular}{|c|c|c|c|}
\hline \multirow[t]{2}{*}{ OMS } & \multicolumn{2}{|c|}{ KATZ } & \multirow[t]{2}{*}{ TOTAL } \\
\hline & PRESENCA & AUSÊNCIA & \\
\hline PRESENÇA & 6 & - & 6 \\
\hline AUSÊNCIA & 1 & 90 & 91 \\
\hline TOTAL & 7 & 90 & 97 \\
\hline
\end{tabular}

Kappa $=0,917$; concordância ótima; $p<0,01$

Ainda que no lado direito fosse observado o dobro de lesões de cárie entre o grupo dos incisivos superiores, a concordância entre ambos os métodos foi considerada ótima (Tabelas 15 e 16). 
Tabela 16 - Número de incisivos superiores esquerdos de pacientes adultos segundo presença de cárie de superfície radicular (tratada ou não) de acordo com critérios propostos por KATZ (1980), modificado e complementado em 1986, 1990 e 1996, e pela OMS (WHO,1997).

\begin{tabular}{|c|c|c|c|}
\hline \multirow[t]{2}{*}{ OMS } & \multicolumn{2}{|c|}{ KATZ } & \multirow{2}{*}{ TOTAL } \\
\hline & PRESENÇA & AUSENNCIA & \\
\hline PRESENÇA & 3 & - & 3 \\
\hline AUSÊNCIA & 1 & 94 & 95 \\
\hline TOTAL & 4 & 94 & 98 \\
\hline
\end{tabular}

Kappa $=0,851$; concordância ótima; $p<0,01$

Analisando as Tabelas 9 a 16, pode-se destacar o fato de ter havido uma simetria entre os grupos de dentes da arcada superior (lados direito e esquerdo) no tocante à concordância entre os métodos propostos por KATZ e pela OMS, exceção apenas feita aos molares.

Tabela 17 - Número de molares inferiores direitos de pacientes adultos segundo presença de cárie de superficie radicular (tratada ou não) de acordo com critérios propostos por KATZ (1980), modificado e complementado em 1986, 1990 e 1996, e pela OMS (WHO,1997).

\begin{tabular}{|c|c|c|c|}
\hline \multirow[t]{2}{*}{ OMS } & \multicolumn{2}{|c|}{ KATZ } & \multirow[t]{2}{*}{ TOTAI } \\
\hline & PRESENÇA & AUSENCIA & \\
\hline PRESENÇA & 3 & - & 3 \\
\hline AUSÊNCIA & 3 & 65 & 68 \\
\hline TOTAL & 6 & 65 & 71 \\
\hline
\end{tabular}

Kappa $=0,646$; concordância boa; $p<0,01$

Com um número menor de dentes examinados em comparação com os molares superiores, observa-se que nos molares inferiores direitos, fora as lesões de cárie de superfície radicular detectadas por ambos os métodos, houve 3 lesões detectadas somente pelo método proposto por KATZ. A concordância foi considerada boa. 
Idêntica concordância à anterior foi encontrada nos molares inferiores esquerdos, mesmo que o número de dentes examinados fosse menor e as lesões de cárie mais do que o dobro (Tabela 18).

Tabela 18 - Número de molares inferiores esquerdos de pacientes adultos segundo presença de cárie de superfície radicular (tratada ou não) de acordo com critérios propostos por KATZ (1980), modificado e complementado em 1986, 1990 e 1996, e pela OMS (WHO,1997).

\begin{tabular}{|c|c|c|c|}
\hline \multirow[t]{2}{*}{$\overline{\mathrm{OMS}}$} & \multicolumn{2}{|c|}{ KATZ } & \multirow[t]{2}{*}{ TOTAL } \\
\hline & PRESENCA & AUSENCIA & \\
\hline PRESENÇA & 7 & - & 7 \\
\hline AUSÊNCIA & 3 & 54 & 57 \\
\hline TOTAL & 10 & 54 & 64 \\
\hline
\end{tabular}

Kappa $=0,797$; concordância boa; $\mathrm{p}<0,01$

Tabela 19 - Número de pré-molares inferiores direitos de pacientes adultos segundo presença de cárie de superfície radicular (tratada ou não) de acordo com critérios propostos por KATZ (1980), modificado e complementado em 1986, 1990 e 1996, e pela OMS (WHO,1997).

\begin{tabular}{|c|c|c|c|}
\hline \multirow[t]{2}{*}{ OMS } & \multicolumn{2}{|c|}{ KATZ } & \multirow[t]{2}{*}{ TOTAL } \\
\hline & PRESENÇA & AUSÊNCIA & \\
\hline PRESENÇA & 13 & - & 13 \\
\hline AUSÊNCIA & 3 & 79 & 82 \\
\hline TOTAL & 16 & 79 & 95 \\
\hline
\end{tabular}

Kappa $=0,878$; concordância ótima; $p<0,01$

Entre os pré-molares inferiores direitos a concordância observada foi ótima, com 3 lesões detectadas somente pelo método proposto por KATZ . 
Tabela 20 - Número de pré-molares inferiores esquerdos de pacientes adultos segundo presença de cárie de superfície radicular (tratada ou não) de acordo com critérios propostos por KATZ (1980), modificado e complementado em 1986, 1990 e 1996, e pela OMS (WHO,1997).

\begin{tabular}{|c|c|c|c|}
\hline \multirow[t]{2}{*}{ OMS } & \multicolumn{2}{|c|}{ KATZ } & \multirow[t]{2}{*}{ TOTAL } \\
\hline & PRESENÇA & AUSENCIA & \\
\hline PRESENÇA & 10 & 1 & 11 \\
\hline AUSÊNCIA & 5 & 91 & 96 \\
\hline TOTAL & 15 & 92 & 107 \\
\hline
\end{tabular}

Kappa $=0,738$; concordância boa; $p<0,01$

Quanto aos pré-molares inferiores esquerdos, a concordância obtida entre os métodos foi boa, observando-se 1 lesão de cárie de superfície radicular detectada somente pelo método proposto pela OMS e 5 detectadas somente pelo método proposto por KATZ.

Tabela 21- Número de caninos inferiores direitos de pacientes adultos segundo presença de cárie de superficie radicular (tratada ou não) de acordo com critérios propostos por KATZ (1980), modificado e complementado em 1986, 1990 e 1996, e pela OMS (WHO,1997).

\begin{tabular}{|c|c|c|c|}
\hline \multirow[t]{2}{*}{ OMS } & \multicolumn{2}{|c|}{ KATZ } & \multirow[t]{2}{*}{ TOTAL } \\
\hline & PRESENÇA & AUSENCIA & \\
\hline PRESENÇA & 5 & - & 5 \\
\hline AUSÊNCIA & 1 & 61 & 62 \\
\hline TOTAL & 6 & 61 & 67 \\
\hline
\end{tabular}

Kappa $=0,901 ;$ concordância ótima; $p<0,01$

No que diz respeito aos caninos inferiores, a concordância observada em ambos os lados foi considerada ótima, mesmo apresentando cada grupo 1 lesão detectada somente pelo método proposto por KATZ e os caninos esquerdos apresentando 1 lesão a mais pelo método proposto pela OMS (Tabelas 21 e 22). 
Tabela 22 - Número de caninos inferiores esquerdos de pacientes adultos segundo presença de cárie de superfície radicular (tratada ou não) de acordo com critérios propostos por KATZ (1980), modificado e complementado em 1986, 1990 e 1996, e pela OMS (WHO, 1997).

\begin{tabular}{|c|c|c|c|}
\hline \multirow[t]{2}{*}{ OMS } & \multicolumn{2}{|c|}{ KATZ } & \multirow[t]{2}{*}{ TOTAL } \\
\hline & PRESENÇA & AUSÊNCIA & \\
\hline PRESENÇA & 6 & 1 & 7 \\
\hline AUSÊNCIA & 1 & 57 & 58 \\
\hline TOTAL & 7 & 58 & 65 \\
\hline
\end{tabular}

Kappa $=0,839$; concordância ótima; $p<0,01$

Tabela 23 - Número de incisivos inferiores direitos de pacientes adultos segundo presença de cárie de superficie radicular (tratada ou não) de acordo com critérios propostos por KATZ (1980), modificado e complementado em 1986, 1990 e 1996, e pela OMS (WHO,1997).

\begin{tabular}{|c|c|c|c|}
\hline \multirow[t]{2}{*}{ OMS } & \multicolumn{2}{|c|}{ KATZ } & \multirow[t]{2}{*}{ TOTAL } \\
\hline & PRESENÇA & AUSÊNCIA & \\
\hline PRESENÇA & 3 & - & 3 \\
\hline AUSÊNCIA & 1 & 124 & 125 \\
\hline TOTAL & 4 & 124 & 128 \\
\hline
\end{tabular}

Kappa $=0,853$; concordância ótima; $\mathrm{p}<0,01$

Quanto aos incisivos inferiores direitos, detectou-se apenas uma lesão somente pelo método proposto por KATZ, determinando uma concordância ótima entre os métodos.

Tabela 24 - Número de incisivos inferiores esquerdos de pacientes adultos segundo presença de cárie de superfície radicular (tratada ou não) de acordo com critérios propostos por KATZ (1980), modificado e complementado em 1986, 1990 e 1996, e pela OMS (WHO,1997).

\begin{tabular}{|c|c|c|c|}
\hline \multirow[t]{2}{*}{ OMS } & \multicolumn{2}{|c|}{ KATZ } & \multirow[t]{2}{*}{ TOTAL } \\
\hline & PRESENÇA & AUSENCIA & \\
\hline PRESENÇA & 2 & 2 & 4 \\
\hline AUSÊNCIA & - & 126 & 126 \\
\hline TOTAL & 2 & 128 & 130 \\
\hline
\end{tabular}

Kappa $=0,659 ;$ concordância boa; $p<0,01$ 
Já para os incisivos inferiores esquerdos, foram observadas 2 lesões de cárie de superficie radicular somente pelo método proposto pela OMS e 2 detectadas por ambos os métodos. Esta situação levou a uma concordância considerada boa.

Na mandíbula, como mostram as Tabelas 17 a 24 , não foi observada uma simetria entre os grupos de dentes em relação aos lados direito e esquerdo no que diz respeito à concordância entre os métodos propostos por KATZ e pela OMS.

\subsubsection{Concordância Segundo Quadrantes da Boca}

Tabela 25 - Número de dentes do quadrante inferior direito de pacientes adultos segundo presença de cárie de superfície radicular (tratada ou não) de acordo com critérios propostos por KATZ (1980), modificado e complementado em 1986, 1990 e 1996, e pela OMS (WHO,1997).

\begin{tabular}{|c|c|c|c|}
\hline \multirow[t]{2}{*}{ OMS } & \multicolumn{2}{|c|}{ KATZ } & \multirow[t]{2}{*}{ TOTAL } \\
\hline & PRESENÇA & AUSÊNCIA & \\
\hline PRESENÇA & 24 & - & 24 \\
\hline AUSÊNCIA & 8 & 329 & 337 \\
\hline TOTAL & 32 & 329 & 361 \\
\hline
\end{tabular}

Kappa $=0,845$; concordância ótima; $p<0,01$

Analisando a concordância entre os métodos propostos por KATZ e pela

OMS nos diferentes quadrantes da boca, observa-se que no quadrante inferior direito foram detectadas 8 lesões de cárie de superficie radicular somente pelo primeiro método e não detectadas pelo segundo, sendo que a concordância foi considerada ótima. 
Tabela 26 - Número de dentes do quadrante inferior esquerdo de pacientes adultos segundo presença de cárie de superficie radicular (tratada ou não) de acordo com critérios propostos por KATZ (1980), modificado e complementado em 1986, 1990 e 1996, e pela OMS (WHO,1997).

\begin{tabular}{|c|c|c|c|}
\hline \multirow[t]{2}{*}{ OMS } & \multicolumn{2}{|c|}{ KATZ } & \multirow[t]{2}{*}{ TOTAI } \\
\hline & PRESENÇA & AUSENNCIA & \\
\hline PRESENÇA & 25 & 4 & 29 \\
\hline AUSÊNCIA & 9 & 328 & 337 \\
\hline TOTAL & 34 & 332 & 366 \\
\hline
\end{tabular}

Kappa $=0,774 ;$ concordância boa; $p<0,01$

Já no quadrante inferior esquerdo, além de 9 lesões de cárie de superficie radicular diagnosticadas apenas pelo método proposto por KATZ, foram detectadas 4 lesões somente pelo método proposto pela OMS, o que levou a uma classificação da concordância como boa.

Tabela 27 - Número de dentes do quadrante superior esquerdo de pacientes adultos segundo presença de cárie de superficie radicular (tratada ou não) de acordo com critérios propostos por KATZ (1980), modificado e complementado em 1986, 1990 e 1996, e pela OMS (WHO,1997).

\begin{tabular}{|c|c|c|c|}
\hline \multirow[t]{2}{*}{ OMS } & \multicolumn{2}{|c|}{ KATZ } & \multirow[t]{2}{*}{ TOTAI } \\
\hline & PRESENÇA & AUSENCIA & \\
\hline PRESENÇA & 20 & - & 20 \\
\hline AUSÊNCIA & 12 & 308 & 320 \\
\hline TOTAL & 32 & 308 & 340 \\
\hline
\end{tabular}

Kappa $=0,751 ;$ concordância boa; $p<0,01$

A maior discrepância nos quadrantes entre os métodos foi observada no superior esquerdo, onde 12 lesões de cárie de superfície radicular foram detectadas somente pelo método proposto por KATZ. Mesmo assim, a concordância foi considerada boa. 
Tabela 28 - Número de dentes do quadrante superior direito de pacientes adultos segundo presença de cárie de superficie radicular (tratada ou não) de acordo com critérios propostos por KATZ (1980), modificado e complementado em 1986, 1990 e 1996, e pela OMS (WHO,1997).

\begin{tabular}{|c|c|c|c|}
\hline \multirow[t]{2}{*}{ OMS } & \multicolumn{2}{|c|}{ KATZ } & \multirow[t]{2}{*}{ TOTAI } \\
\hline & PRESENÇA & AUSENNCIA & \\
\hline PRESENÇA & 23 & 1 & 24 \\
\hline AUSÊNCIA & 8 & 312 & 320 \\
\hline TOTAL & 31 & 312 & 344 \\
\hline
\end{tabular}

Kappa $=0,822$; concordância ótima; $p<0,01$

Finalmente, com 8 lesões de cárie de superficie radicular detectadas somente pelo método proposto por KATZ e 1 somente pelo método proposto pela OMS, a concordância foi considerada ótima no quadrante superior direito.

\subsubsection{Concordância Segundo Arcadas da Boca}

Tabela 29 - Número de dentes da arcada superior de pacientes adultos segundo presença de cárie de superfície radicular (tratada ou não) de acordo com critérios propostos por KATZ (1980), modificado e complementado em 1986, 1990 e 1996, e pela OMS (WHO,1997).

\begin{tabular}{|c|c|c|c|}
\hline \multirow[t]{2}{*}{ OMS } & \multicolumn{2}{|c|}{ KATZ } & \multirow[t]{2}{*}{ TOTAL } \\
\hline & PRESENÇA & AUSÊNCIA & \\
\hline PRESENÇA & 43 & 1 & 44 \\
\hline AUSÊNCIA & 20 & 620 & 640 \\
\hline TOTAL & 63 & 621 & 684 \\
\hline
\end{tabular}

Kappa $=0,787$; concordância boa; $\mathbf{p}<0,01$

$\mathrm{Na}$ arcada superior observa-se uma concordância entre os métodos de exame de cárie de superfície radicular considerada boa, apesar de que 20 lesões foram detectadas somente pelo método proposto por KATZ e apenas 1 pelo método proposto pela $\mathbf{O M S}$. 
Tabela 30 - Número de dentes da arcada inferior de pacientes adultos segundo presença de cárie de superfície radicular (tratada ou não) de acordo com critérios propostos por KATZ (1980), modificado e complementado em 1986, 1990 e 1996, e pela OMS (WHO,1997).

\begin{tabular}{|c|c|c|c|}
\hline \multirow[t]{2}{*}{ OMS } & \multicolumn{2}{|c|}{ KATZ } & \multirow[t]{2}{*}{ TOTAI } \\
\hline & PRESENCA & AUSENCIA & \\
\hline PRESENÇA & 49 & 4 & 53 \\
\hline AUSÊNCIA & 17 & 657 & 674 \\
\hline TOTAL & 66 & 661 & 727 \\
\hline
\end{tabular}

Kappa $=0,808$; concordância ótima; $\mathrm{p}<0,01$

Em relação à arcada inferior foi observado um número menor de lesões detectadas somente pelo método proposto por KATZ em comparação com a arcada superior (17 e 20 respectivamente), o que levou a uma concordância melhor, ou seja, considerada ótima.

\subsubsection{Concordância Segundo Lados da Boca}

Tabela 31 - Número de dentes do lado direito de pacientes adultos segundo presença de cárie de superfície radicular (tratada ou não) de acordo com critérios propostos por KATZ (1980), modificado e complementado em 1986, 1990 e 1996, e pela OMS (WHO,1997).

\begin{tabular}{|c|c|c|c|}
\hline \multirow[t]{2}{*}{ OMS } & \multicolumn{2}{|c|}{ KATZ } & \multirow[t]{2}{*}{ TOTAL } \\
\hline & PRESENÇA & AUSENCIA & \\
\hline PRESENÇA & 47 & 1 & 48 \\
\hline AUSÊNCIA & 16 & 641 & 657 \\
\hline TOTAL & 63 & 642 & 705 \\
\hline
\end{tabular}

Kappa $=0,834 ;$ concordância ótima; $p<0,01$

No lado direito da boca a concordância foi considerada ótima, mesmo tendo sido registradas 16 lesões detectadas somente pelo método proposto por KATZ e 1 apenas pelo método proposto pela OMS. 
Tabela 32 - Número de dentes do lado esquerdo de pacientes adultos segundo presença de cárie de superfície radicular (tratada ou não) de acordo com critérios propostos por KATZ (1980), modificado e complementado em 1986, 1990 e 1996, e pela OMS (WHO,1997).

\begin{tabular}{|c|c|c|c|}
\hline \multirow[t]{2}{*}{$\overline{\text { OMS }}$} & \multicolumn{2}{|c|}{ KATZ } & \multirow[t]{2}{*}{ TOTAL } \\
\hline & PRESENÇA & AUSENCIA & \\
\hline PRESENÇA & 45 & 4 & 49 \\
\hline AUSÊNCIA & 21 & 636 & 657 \\
\hline TOTAL & 66 & 640 & 706 \\
\hline
\end{tabular}

Kappa $=0,763 ;$ concordância boa; $p<0,01$

Quanto ao lado esquerdo, o valor obtido para o Kappa foi menor comparado ao lado direito, sugerindo uma concordância boa entre os métodos de exame de cárie de superfície radicular propostos por KATZ e pela OMS, o que pode ser explicado pelo maior número de lesões detectadas por ambos os métodos isoladamente, que no caso dos dentes do lado direito.

\subsubsection{Concordância para a Boca como um Todo}

Tabela 33 - Número de dentes de pacientes adultos segundo presença de cárie de superfície radicular (tratada ou não) de acordo com critérios propostos por KATZ (1980), modificado e complementado em 1986, 1990 e 1996, e pela OMS (WHO, 1997).

\begin{tabular}{|c|c|c|c|}
\hline \multirow[t]{2}{*}{ OMS } & \multicolumn{2}{|c|}{ KATZ } & \multirow[t]{2}{*}{ TOTAL } \\
\hline & PRESENÇA & AUSENCIA & \\
\hline PRESENÇA & 92 & 5 & 97 \\
\hline AUSÊNCIA & 37 & 1277 & 1314 \\
\hline TOTAL & 129 & 1282 & 1411 \\
\hline
\end{tabular}

Kappa $=0,798 ;$ concordância boa; $\mathrm{p}<0,01$ 
Para a boca como um todo, a concordância entre os métodos de exame de cárie de superfície radicular foi considerada boa (Kappa $=0,798)$, tendo sido detectadas 37 lesões somente pelo método proposto por KATZ e 5 apenas pelo método proposto pela OMS. Segundo PEREIRA (1995), a partir de 0,81 a concordância pode ser considerada como ótima.

Em resumo, a concordância entre os critérios propostos por KATZ (1980), modificado e complementado em 1986, 1990 e 1996, e pela OMS (WHO,1997) observada nos diferentes locais da boca esteve entre boa e ótima, sendo que a melhor concordância foi obtida para a arcada inferior e o lado direito da boca.

Pode-se salientar o fato de ter havido um maior número de dentes apresentando lesão de cárie de superfície radicular segundo os critérios propostos por KATZ (1980), modificado e complementado em 1986,1990 e 1996. Apesar disso, o número médio de dentes apresentando lesões radiculares foi de 1,43 (desvio padrão=2,42) segundo critérios propostos pela OMS (WHO,1997) e de 1,96 (desvio padrão=2,64) segundo critérios propostos por KATZ (1980), modificado e complementado em 1986,1990 e 1996), valores estatisticamente semelhantes $(p<0,01)$. Além disso, houve uma boa correlação entre os dois critérios, pois o Coeficiente de Correlação de Pearson foi 0,94. 
6-DISCUSSÃO 
Até o final da década de 70 vários estudos foram realizados com o objetivo de descrever a epidemiologia da cárie de superfície radicular em diversas populações e faixas etárias (LEIGH, 1935; HARDWICK, 1960; MEHTA e SCHOFF, 1965; CORBETT E MOORE, 1971; SCHAMSCHULA e col., 1972; JORDAN E SUMNEY, 1972; SUMNEY e col., 1973; BANTING e COURTRIGHT, 1975). O aumento da ocorrência da doença, devido, principalmente, ao aumento da população idosa no mundo e ao fato dos adultos e idosos conservarem por mais tempo os dentes na boca, particularmente nos países desenvolvidos, exigia esse conhecimento. Porém, a comunidade científica se ressentia de critérios de diagnóstico e avaliação melhor definidos em relação à doença, o que proporcionaria maior segurança no tocante a comparações entre os diversos trabalhos que estavam sendo realizados.

Após a publicação do Índice de Cárie Radicular (ICR) por KATZ em 1980, vários autores o adotaram e várias críticas ao índice também foram feitas. As principais diziam respeito à definição de presença de retração gengival, à não inclusão de lesões sub-gengivais e à não inclusão de dentes perdidos no cálculo do índice. O autor se manifestou a respeito em duas ocasiões: em 1990 e em 1996, defendendo seu ponto de vista em relação à manutenção do cálculo do índice como havia sido proposto e colaborou para a definição de critérios de diagnóstico com a publicação de convenções para o exame de cárie de superficie radicular em 1986 e 1990.

WATANABE (1994), utilizando o método proposto por KATZ (1980), modificado e complementado em 1986 e 1990, verificou a necessidade e a 
importância de ter critérios os mais objetivos possíveis, pois existe uma dificuldade inerente às características da doença, ou seja, localização das lesões, caracterização da retração gengival e restaurações que envolvem coroa e raiz, que dificultam o registro da lesão de cárie de superfície radicular.

Em 1997 a Organização Mundial da Saúde (OMS) publicou novas orientações para levantamentos epidemiológicos em saúde bucal. Até então, a OMS havia publicado três edições do manual e somente nesta última apresentou, pela primeira vez, critérios de diagnóstico para registro de cárie de superfície radicular.

Os critérios para avaliação da ocorrência de cárie de superfície radicular propostos por KATZ (1980), modificado e complementado em 1986, 1990, 1996, e pela OMS (WHO, 1997) são coincidentes em vários aspectos, porém divergentes em alguns. Os que poderiam interferir na medição da doença são os que se relacionam com lesões que envolvem coroa e raiz, tanto tratadas como não tratadas. No caso de lesões não tratadas, que envolvem coroa e raiz, KATZ considera qualquer lesão na raiz próxima à junção cemento-esmalte, independente da condição do esmalte. Já a OMS considera a raiz cariada apenas quando se julgar que a lesão se originou nesta região e se estendeu para a coroa, se a raiz necessita de tratamento em separado ou se houver dúvida quanto à origem da lesão. O mesmo critério se aplica, segundo a OMS, para restaurações que envolvem coroa e raiz, enquanto KATZ sugere que, neste caso, a raiz seja considerada restaurada se a restauração se estender por pelo menos $3 \mathrm{~mm}$ além da junção cemento-esmalte. Em ambos os casos, o critério sugerido por KATZ parece ser mais objetivo que o proposto pela OMS, não estando 
baseado no julgamento subjetivo do examinador como neste último caso, mas em situações concretas, ou seja, presença ou não de lesão na raiz e restauração se estendendo por $3 \mathrm{~mm}$ ou mais além da junção cemento-esmalte.

Alguns aspectos discordantes não interferem diretamente na medição da cárie de superfície radicular. Quando da presença de coroas totais, KATZ (1980), modificado e complementado em 1986, 1990 e 1996, recomenda que nunca seja anotada a raiz como restaurada e a OMS (WHO, 1997) não orienta especificamente; neste caso, aplica-se o critério para restaurações que envolvem coroa e raiz. Outra situação diz respeito aos critérios de exclusão da superficie ou dente a ser examinado: KATZ sugere que a superficie ou dente com $20 \%$ de sua porção radicular inacessível ao exame seja excluído, enquanto que a OMS não especifica tanto, sugerindo apenas a exclusão do dente na presença de cálculo em uma extensão que impossibilite o exame. Já em relação à exclusão de indivíduos da amostra, KATZ recomenda que uma pessoa com mais de $10 \%$ de suas superficies radiculares anotadas como "ilegíveis" não participe da população de estudo, enquanto que a OMS não faz menção a este respeito.

No presente estudo participaram dos exames pessoas entre 36 e 78 anos, com idade média de 47,87 anos. Destaca-se o fato de $50,7 \%$ pertencerem à faixa etária de 35 a 44 anos, a qual é recomendada pela OMS (WHO, 1997) para acompanhamento das condições de saúde bucal na população adulta. A grande maioria das pessoas examinadas era do sexo feminino $(71,6 \%)$. Em um estudo realizado com o objetivo de conhecer alguns aspectos sócio-econômicos dos pacientes atendidos nas clínicas 
da Faculdade de Odontologia de Ribeirão Preto - USP, WATANABE e col. (1997) entrevistaram 532 pessoas e observaram que $70,7 \%$ pertenciam ao sexo feminino e $56,4 \%$ possuiam idade entre 18 e 50 anos. Entre os entrevistados, 55,7\% relataram uma renda familiar mensal de até 4 salários mínimos vigentes na época e 50,2\% não haviam completado o primeiro grau.

Analisando a ocorrência de cárie de superficie radicular na população de estudo (Tabelas 2 e 7), observou-se uma proporção maior de pessoas com pelo menos uma lesão de cárie radicular pelo método proposto por KATZ $(64,2 \%)$ que pelo método proposto pela OMS $(55,2 \%)$. Nesse aspecto, existe uma variação grande entre os trabalhos pesquisados. Entre os que aplicaram o método proposto por KATZ (1980), destacam-se o estudo realizado por KATZ e col. (1982), no qual foram examinadas 473 pessoas com idade entre 20 e 64 anos, onde foi observada uma proporção menor de pessoas exibindo uma ou mais lesões de cárie de superficie radicular $(42,0 \%)$. Outros estudos utilizaram populações de idade mais avançada: WALLACE e col. (1988) examinaram americanos com 60 anos ou mais e $69,7 \%$ deles apresentaram pelo menos uma lesão de cárie de superfície radicular; FURE e ZICKERT (1990) encontraram 89,0\% de um grupo de suecos aos 55, 65 e 75 anos nestas condições; e FEJERSKOV e col. (1991), avaliando a ocorrência de cárie de superficie radicular em pacientes dinamarqueses de 60 a 80 anos, encontraram $60 \%$ deles com experiência da doença. Alguns estudos realizados não utilizaram o Índice de Cárie Radicular (ICR) proposto por KATZ (1980) e também mostraram considerável variação na proporção de pessoas exibindo pelo menos uma lesão de cárie de superficie radicular: BECK e col. (1985) e GRAVES e col. (1992) 
utilizaram americanos com idade igual ou superior a 65 anos e observaram valores de $63,0 \%$ e 43,7\% respectivamente; já LOCKER e col. (1989) examinaram um grupo de canadenses com idade inferior (50 anos ou mais) e encontraram $56,8 \%$ deles com alguma lesão de cárie de superfície radicular.

Os resultados apresentados nas Tabelas 4 e 8 mostraram, em ambos os métodos de exame, que mais da metade dos dentes presentes apresentaram recessão gengival $(54,8 \%$-KATZ e $57,2 \%$-OMS). Entre estes, a grande maioria $(83,2 \%-\mathrm{KATZ}$ e $88,2 \%$-OMS) apresentava superficies radiculares hígidas. Entre os que apresentavam lesão de cárie radicular, aproximadamente a metade $(48,8 \%-\mathrm{KATZ}$ e 42,7\%-OMS) estava tratada. Dados semelhantes foram obtidos por LOCKER e col. (1989), que apresentaram uma proporção de 50\%, e por GRAVES e col. (1992), cujo estudo realizado com idosos americanos mostrou que $52,9 \%$ dos dentes com lesão estavam tratados.

Em relação ao número médio de superfícies atacadas pela doença o valor observado $(2,27)$ se mostrou preocupante por se tratar de um grupo de pessoas com idade média de 47,87 anos, já que foi semelhante ao relatado em estudos realizados com grupos de pessoas de idade mais avançada, como os de BECK e col. (1985), os quais realizaram um estudo com 520 idosos com 65 anos ou mais e encontraram uma média de 2,3 superfícies com lesões de cárie de superficie radicular, enquanto LOCKER e col. (1989), examinando 183 pessoas com idade igual ou superior a 50 anos, observaram, em média, 2,6 superfícies radiculares atacadas por cárie. 
Quanto ao ICR médio obtido neste estudo (média=16,21\%; $\mathrm{IC}_{95 \%}=$ $11,28 \% \longmapsto 21,14 \%$ ), este situa-se próximo ao observado por KATZ e col. (1985), os quais examinaram 3.361 pacientes de 20 a 79 anos e encontraram um ICR médio igual a $15 \%$. Avaliando uma população com idade semelhante à que compôs o estudo de KATZ e col. (1985), GUSTAVSEN e col. (1988) obtiveram um ICR médio ligeiramente maior, ou seja, de $21 \%$. Em uma revisão de trabalhos realizados sobre o assunto KATZ (1985) estimou que a ocorrência média de cárie de superficie radicular em populações adultas de países ocidentais industrializados situa-se entre 20 e $40 \%$.

No que diz respeito à variação do ICR nos grupos de dentes (Figura 1), os maiores valores apresentados pelos molares inferiores $(28,07 \%)$ e os menores pelos incisivos inferiores $(3,4 \%)$, estão de acordo com os relatados por KATZ e col. (1982), KATZ e col. (1985) e FURE e ZICKERT (1990).

No tocante à ocorrência de cárie radicular nas superfícies dentárias, as que apresentaram os maiores valores para o ICR foram as vestibulares e proximais (Figura 3), à semelhança do que foi encontrado por KATZ e col. (1985), GUSTAVSEN e col. (1988) e FURE e ZICKERT (1990) e os menores valores foram as linguais. KATZ e col. (1982) sugerem que existam fatores intra-orais específicos agindo no sentido de determinar esta variação no padrão de ataque de cárie de superfície radicular e que estes deveriam ser objeto de estudos mais aprofundados. FURE e ZICKERT (1990), por sua vez, colocam que uma explicação para os altos índices de cárie de superfície radicular nas superficies 
vestibulares dos molares inferiores poderia ser que eles estão expostos ao risco de desenvolver a doença mais cedo; outra explicação poderia ser que eles estariam restaurados por outras razões que não a cárie, como a erosão e a abrasão, condições observadas com freqüência nestas superficies. Chama a atenção o comportamento das superfícies mesiais: apesar de apresentarem o menor valor médio de superfícies radiculares atacadas por cárie (Figura 2), mudam de posto em relação ao risco de desenvolver a doença uma vez estando exposta a superficie radicular, mostrando o terceiro maior ICR (Figura 3).

Observando-se as Tabelas 9 a 33, nota-se que houve 37 lesões de cárie de superfície radicular registradas apenas quando da aplicação do método proposto por KATZ (1980), modificado e complementado em 1986, 1990 e 1996, e 5 lesões registradas apenas quando da aplicação do método proposto pela OMS (WHO, 1997). Entre as primeiras, 31 referiam-se a lesões de cárie de superficie radicular envolvendo coroa e raiz (17 não tratadas e 14 tratadas), as quais, segundo os critérios propostos pela OMS, deveriam ser registradas para a coroa, seu local provável de origem, e não para a raiz. Estas. lesões fariam parte somente do cálculo do Índice CPO-D, porém não do número médio de dentes com cárie de superfície radicular, o que explicaria a discrepância entre os dois métodos.

No entanto, esta divergência de critérios e, conseqüentemente, divergência numérica na medição da ocorrência de cárie de superfície radicular não foi suficiente, do ponto de vista estatístico, para alterar significativamente o número médio de dentes apresentando lesões da doença, por ambos os métodos. Ainda, 
conservou-se a correlação entre as duas formas de medir a ocorrência de cárie de superficie radicular.

No que diz respeito à concordância entre os critérios propostos por KATZ (1980), modificado e complementado em 1986, 1990 e 1996, e pela OMS (WHO, 1997) medida pela estatística Kappa, esta apresentou-se entre boa e ótima nas diferentes áreas da boca (grupos de dentes, quadrantes, arcadas e lados). Destacam-se o lado direito e a arcada inferior como apresentando uma concordância considerada ótima. Em relação à boca como um todo, a concordância entre os dois critérios foi boa, porém bastante próxima ao limite superior da classificação. Novamente, o que pode ter influenciado esses resultados foi a presença de lesões, tratadas ou não, envolvendo coroa e raiz, não registradas para esta última, de acordo com os critérios propostos pela OMS (WHO, 1997). HUNT e BECK (1985) já haviam chamado atenção para o fato de terem observado, durante a calibração de examinadores para levantamentos epidemiológicos que envolviam exame de superficies radiculares, dificuldades de concordância entre os examinadores quanto à origem das lesões que envolviam coroa e raiz. De forma mais profunda, DE PAOLA e col. (1989), em um estudo cujo objetivo era verificar o efeito, entre outros fatores, da inclusão de lesões ou restaurações que envolviam superfícies coronárias e radiculares sobre a quantificação de cárie de superficie radicular, observaram que as lesões de superfície radicular eram responsáveis por um aumento de 17 pontos na porcentagem de pessoas afetadas pela doença, enquanto que o número médio de dentes afetados e o ICR médio praticamente dobravam. Segundo esses autores, estes componentes deveriam ser incluídos na avaliação da prevalência da doença porque 
eles representam parte do problema de cárie de superfície radicular. Estima-se que exista uma tendência do examinador em julgar a origem primária deste tipo de lesão como sendo na coroa, já que esta é exposta por mais tempo aos fatores do meio bucal que influenciam a ocorrência da cárie dentária. Nesse caso, a lesão, segundo os critérios propostos pela OMS(WHO, 1997), seria registrada para a coroa, o que, em um levantamento epidemiológico de condições gerais de ocorrência da cárie dentária estaria garantindo o cômputo da lesão quando do cálculo do Índice CPO-D, mas não quando da avaliação da ocorrência de cárie de superficie radicular especificamente.

Assim, os métodos mostraram resultados semelhantes, do ponto de vista estatístico, na avaliação da ocorrência de cárie de superfície radicular no grupo de pessoas examinadas. Uma vantagem do método proposto por KATZ (1980), modificado e complementado em 1986, 1990 e 1996 é o fato dos critérios serem mais objetivos, ou seja, estão baseados em situações mais concretas, evitando a necessidade de julgamento subjetivo por parte do examinador. Ainda, estes critérios são mais abrangentes que os propostos pela OMS (WHO, 1997), pois definem as categorias de registro quando da presença de coroas totais, de cáries recorrentes e também definem regras de exclusão do indivíduo da amostra. Por outro lado, o fato do método proposto pela OMS (WHO, 1997) ser amplamente divulgado e utilizado por pesquisadores de várias partes do mundo permite que comparações entre populações diversas possam ser feitas e aumenta a perspectiva de realização de mais pesquisas sobre o assunto, o que certamente beneficia o aprimoramento dos métodos propostos. 
7- CONCLUSÕES 
7.1. Existem divergências entre os critérios propostos por KATZ (1980), modificado e complementado em 1986, 1990 e 1996 e pela OMS (WHO, 1997) para avaliação da ocorrência de cárie de superfície radicular, principalmente no que diz respeito às lesões, tratadas ou não, que envolvem coroa e raiz.

7.2. Houve um número maior de lesões de cárie de superficie radicular detectadas segundo os critérios propostos por KATZ (1980), modificado e complementado em 1986, 1990 e 1996. Entretanto, o número médio de dentes que apresentaram lesões de cárie de superfície radicular segundo ambos os métodos foi semelhante do ponto de vista estatístico, bem como foi observada correlação entre os mesmos.

7.3. Os resultados mostraram uma concordância classificada como boa entre os critérios propostos por KATZ (1980), modificado e complementado em 1986, 1990 e 1996, e pela OMS (WHO, 1997) para avaliação da ocorrência de cárie de superfície radicular. 
8-REFERÊNCIAS BIBLIOGRÁFICAS 
1. Aherne CA, O'Mullane D, Barret BE. Indices of root surface caries. J Dent Res 1990; 69: 1222-6.

2. Banting DW. Epidemiology of root caries. Gerodontology 1986; 5: 5-11.

3. Banting DW. Diagnosis and prediction of root caries. Adv Dent Res 1993; 7: 80-6.

4. Banting DW, Courtright PN. Distribution and natural history of carious lesions on the roots of teeth. J Can Dent Assoc 1975; 41: 45-9.

5. Banting DW, Ellen RP, Fillery ED. Prevalence of root surface caries among institutionalized older persons. Community Dent Oral Epidmiol 1980; 8: 84-8.

6. Beck J. The epidemilogy of root caries surface. J Dent Res 1990; 69: 121621.

7. Beck JD, Hunt RJ, Hand JS, Field HM. Prevalence of root and coronal caries in a noninstitutionalized older population. J Am Dent Assoc 1985; 111: $964-$ 7.

8. Beck JD. The epidemiology of root surface caries: North American studies. Adv Dent Res 1993; 7: 42-51.

9. Berquó ES, Souza JMP, Gotlieb SLD. Bioestatística. São Paulo: EPU; 1981. 
10. Brustman BA. Impact of exposure to fluoride-adequate water on root surface caries in elderly. Gerodontics $1986 ; 2: 203-7$.

11. Centers for Disease Control, World Health Organization. Epi-Info. Epidemiologia em microcomputadores: um sistema de processamento de texto, banco de dados e estatísticas [ Programa de computador] Versão 5.01. Atlanta: OPAS/WHO; 1991

12. Cohen JA. Coefficient of agreement for nominal scales. Educational and psychological measurement $1960 ; 20: 37-46$.

13. Corbett ME, Moore WJ. Distribution of caries in acient British populations. $\mathbf{J}$ Dent Res 1971; 50: 663. [ Abstract 28]

14. De Paola PF, Soparkar DM, Kent RL. Methodological issues relative to the quantification of root surface caries. Gerodontology 1989; 8: 3-8.

15. Fejerskov O, Luan WM, Nyvad B, Budtz-Jorgensen E, Holm-Pederson P. Active and inactive root surface caries lesions in a selected group of 60 - to 80-year-old Danes. Caries Res 1991; 25: 385-91.

16. Fejerskov O, Baelum V, Ostergaard ES. Root caries in Scandinavia in the 1980's and the future trends to be expected in dental caries experience in adults. Adv Dent Res 1993; 7: 4-14. 
17. Fure S, Zickert I. Prevalence of root surface caries in 55, 65, and 75-year-old Swedish individuals. Community Dent Oral Epidemiol 1990; 18: 100-5.

18. Graves RC, Beck JD, Disney JA, Drake CW. Root caries prevalence in black and white North Carolina adults over age 65. J Public Health Dent 1992; 52: 92-101.

19. Gustavsen F, Clive JM, Tveit AB. Root caries prevalence in a Norwegian adult dental patient population. Gerodontics 1988; 4: 219-23.

20. Hardwick JL. The incidence and distribution of caries throughout the ages in relation to Englishman's diet. Br Dent J 1960; 108: 9-17.

21. Hellyer PH, Beighton D, Heath MR, Lynch EJR. Root caries in older people attending a general dental practice in East Sussex. Br dent J 1990; 169: 2016.

22. Hunt RJ, Beck JD. Methodological considerations in a dental epidemiologic survey of an elderly population. Public Health Dent 1985; 45: 257-60.

23. Jordan H, Sumney DL. Root surface caries: review of the literature and significance of the problem. J Periodontol 1973; 44: 158-63.

24. Katz RV. Assessing root caries in populations: the evolution of root caries index. J Public Health Dent 1980; 40: 7-16. 
25. Katz RV, Hazen SP, Chilton NM, Mumma RD. Prevalence and intraoral distribution of root caries in an adult population. Caries Res 1982; 16: 26571.

26. Katz RV. Development of an index for the prevalence of root caries. J Dent Res 1984; 63 (nºsp.): 814-8.

27. Katz RV. Root caries. Is it the caries problem of the future? J Can Dent Assoc $1985 ; 51: 511-5$.

28. Katz RV, Newitter DA, Clive JM. Root caries prevalence in adult dental patients. J Dent Res 1985; 64: 293. [Abstract 1069].

29. Katz RV. The clinical identification of root caries. Gerodontology 1986; 5: 21-4.

30. Katz RV. Clinical signs of roots caries: measurement issues from an epidemiologic perspective. J Dent Res 1990; 69: 1211-5.

31. Katz RV. The RCI revised after 15 years: used, reinvented, modified, debated, and natural logged. Public Health Dent 1996; 56: 28-34.

32. Leigh RW. Notes on the stomatology and pathology of ancient Egypt. J Am Dent Assoc 1935; 22: 199-222. 
33. Leske GS, Ripa LW. Three-year root caries increments: implications for clinical trials. J Public Health Dent 1989; 49: 142-6.

34. Locker D, Slade GD, Leake JL. Prevalence of and factors associated with root decay in older adults in Canada. J Dent Res 1989; 68: 768-72.

35. Mehta FS, Schroff BC. Aspects of dental diseases in the Indian aborigines. Int Dent J 1965; 15: 182-9.

36. Mumma RD. Development of an index for the prevelence of root caries: discussion of Dr. Katz'presentation. J Dent Res 1984; 63 ( $\mathrm{n}^{\circ}$ esp.): 818-9.

37. Pereira MG. Epidemiologia: teoria e prática. Rio de Janeiro: Guanabara Koogan; 1995.

38. Ravald N, Hamp SE. Prediction of root surface caries in patients treated for advanced periodontal disease. J Clin Periodontol 1981; 8: 400-14.

39. Ravald N, Hamp SE, Birkhed D. Long-term evaluation of root surface caries in periodontally treated patients. J Clin Periodontol 1986; 13: 758-67.

40. Schamschula RG, Keyes PH, Hornabrook RW. Root surface caries in Lufa, New Guinea. 1. Clinical observations. J Am Dent Assoc 1972; 85: 603-8.

41. Servicio Galego de Saúde. Epidat: análisis epidemiológico de datos tabulados [programa de computador]. Galicia: OPAS/WHO; 1994. 
42. Silva SRC. Autopercepção das condições bucais em pessoas com 60 anos e mais de idade. São Paulo; 1999. [ Tese de Doutorado - Faculdade de Saúde Pública da USP]

43. Sumney DL, Jordan HV, Eenglander HR. The prevalence of root surface caries in selected populations. J Periodontol 1973; 44: 500-4.

44. Vehkalahti MM, Rajala M, Tuominen R, Paunio I. Prevalence of root careis in the adult Finnish population. Community Dent Oral Epidemiol 1983; 11: $188-90$

45. Wallace MC, Retief DH, Bradley EL. Prevalence of root caries in a population of older adults. Gerodontics 1988; 4: 84-9.

46. Watanabe MGC. Experiência de cárie de superfície radicular em adultos atendidos na Faculdade de Odontologia de Ribeirão Preto - USP. 19931994. São Paulo; 1994. [ Dissertação de Mestrado - Faculdade de Saúde Pública da USP]

47. Watanabe MGC, Agostinho AM, Moreira A. Aspectos sócio-econômicos dos pacientes atendidos nas clínicas da Faculdade de Odontologia de Ribeirão Preto - USP. Rev Odontol Univ São Paulo 1997; 11: 147-51.

48. World Heslth Organization. Oral health survey: basic methods. $4^{\mathrm{a}}$ ed. Geneva; 1997. 
ANEXOS 


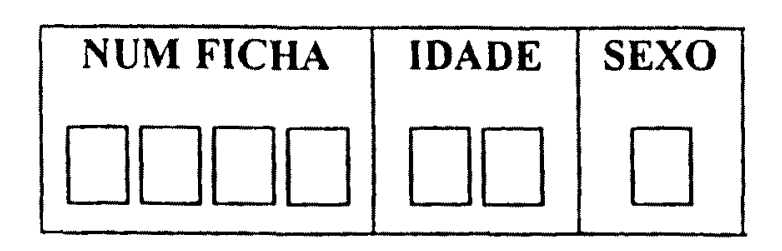
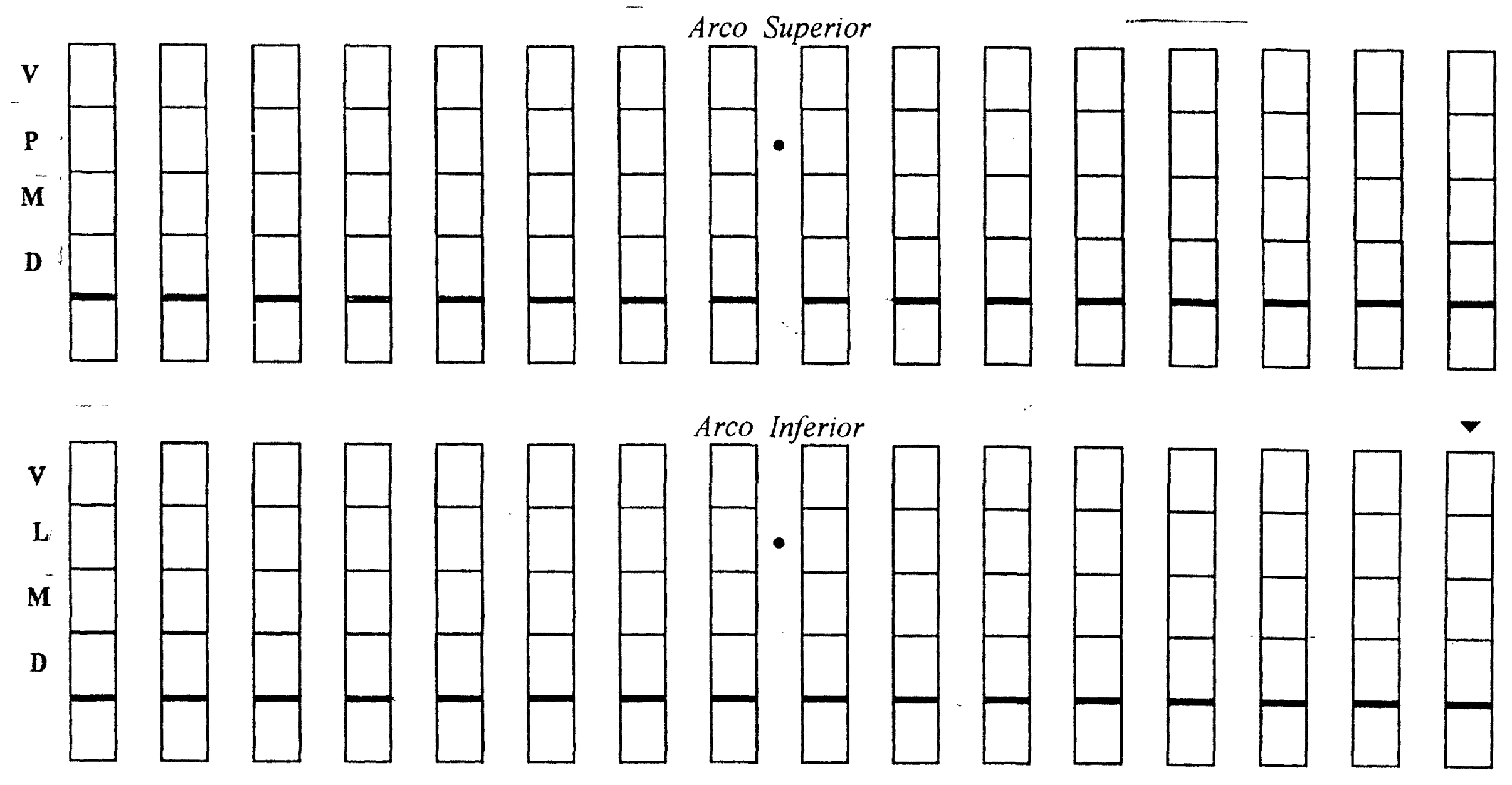


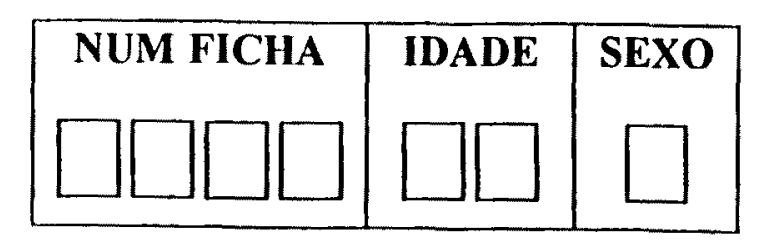

NOME:
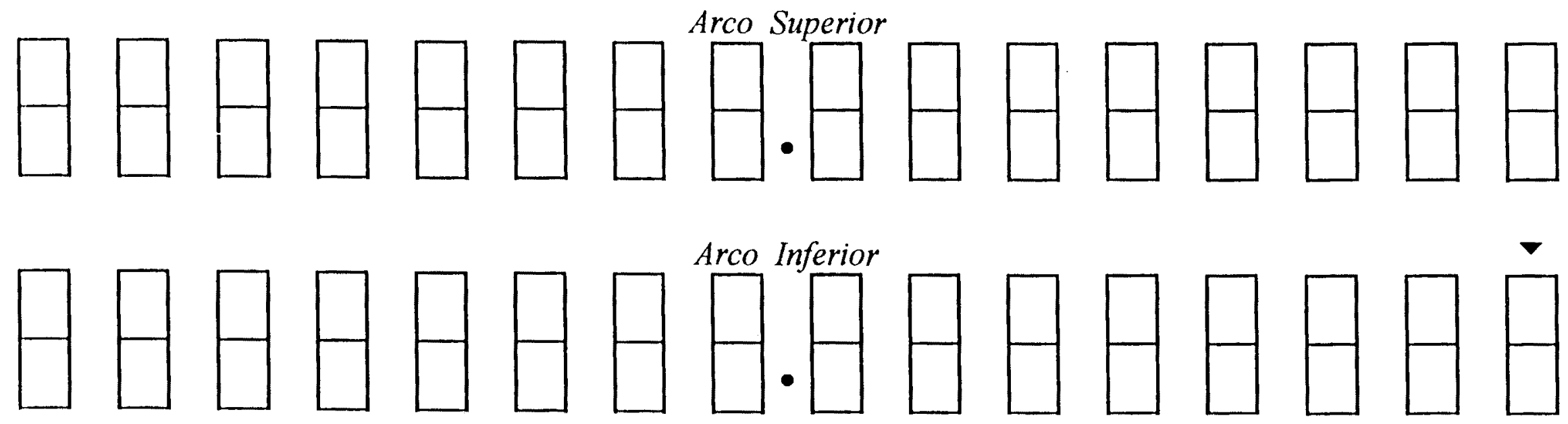